\title{
Article \\ Monitoring Human Milk $\beta$-Casein Phosphorylation and $O$-Glycosylation Over Lactation Reveals Distinct Differences between the Proteome and Endogenous Peptidome
}

\author{
Kelly A. Dingess ${ }^{1,2}{ }^{\mathbb{D}}$, Inge Gazi ${ }^{1,2}$, Henk W. P. van den Toorn ${ }^{1,2} \mathbb{D}$, Marko Mank $^{3} \mathbb{D}$, Bernd Stahl ${ }^{3,4} \mathbb{D}^{\text {, }}$ \\ Karli R. Reiding 1,2,*D and Albert J. R. Heck 1,2,*
}

1 Biomolecular Mass Spectrometry and Proteomics, Bijvoet Center for Biomolecular Research, Utrecht Institute for Pharmaceutical Sciences, University of Utrecht, $3584 \mathrm{CH}$ Utrecht, The Netherlands; k.a.dingess@uu.nl (K.A.D.); i.gazi@uu.nl (I.G.); H.W.P.vandenToorn@uu.nl (H.W.P.v.d.T.)

2 Netherlands Proteomics Center, $3584 \mathrm{CH}$ Utrecht, The Netherlands

3 Danone Nutricia Research, 3584 CT Utrecht, The Netherlands; Marko.MANK@danone.com (M.M.); bernd.stahl@danone.com (B.S.)

4 Chemical Biology \& Drug Discovery, Utrecht Institute for Pharmaceutical Sciences, University of Utrecht, 3584 CG Utrecht, The Netherlands

* Correspondence: k.r.reiding@uu.nl (K.R.R.); a.j.r.heck@uu.nl (A.J.R.H.)

Citation: Dingess, K.A.; Gazi, I.; van den Toorn, H.W.P.; Mank, M.; Stahl,

B.; Reiding, K.R.; Heck, A.J.R.

Monitoring Human Milk $\beta$-Casein

Phosphorylation and $O$-Glycosylation

Over Lactation Reveals Distinct

Differences between the Proteome and Endogenous Peptidome. Int. J. Mol. Sci. 2021, 22, 8140. https:// doi.org/10.3390/ijms22158140

Academic Editor:

Giuseppe Lazzarino

Received: 31 May 2021

Accepted: 22 July 2021

Published: 29 July 2021

Publisher's Note: MDPI stays neutral with regard to jurisdictional claims in published maps and institutional affiliations.

Copyright: (C) 2021 by the authors Licensee MDPI, Basel, Switzerland. This article is an open access article distributed under the terms and conditions of the Creative Commons Attribution (CC BY) license (https:// creativecommons.org/licenses/by/ $4.0 /)$.
Abstract: Human milk is a vital biofluid containing a myriad of molecular components to ensure an infant's best start at a healthy life. One key component of human milk is $\beta$-casein, a protein which is not only a structural constituent of casein micelles but also a source of bioactive, often antimicrobial, peptides contributing to milk's endogenous peptidome. Importantly, post-translational modifications (PTMs) like phosphorylation and glycosylation typically affect the function of proteins and peptides; however, here our understanding of $\beta$-casein is critically limited. To uncover the scope of proteoforms and endogenous peptidoforms we utilized mass spectrometry (LC-MS/MS) to achieve in-depth longitudinal profiling of $\beta$-casein from human milk, studying two donors across 16 weeks of lactation. We not only observed changes in $\beta$-casein's known protein and endogenous peptide phosphorylation, but also in previously unexplored $O$-glycosylation. This newly discovered PTM of $\beta$-casein may be important as it resides on known $\beta$-casein-derived antimicrobial peptide sequences.

Keywords: human milk; mass spectrometry; O-glycosylation; peptidomics; antimicrobial peptides

\section{Introduction}

Human milk is a diverse biofluid, providing unique nutritional, non-nutritional, and bioactive components to the infant. There are many factors that affect the composition of human milk throughout lactation, including maternal factors such as diet, age, and body mass index and infant factors such as gestational age and sex, as well as a range of influences from the environment, physiology, and behavior [1-3]. Among the many different components (sugars, lipids, etc.) of human milk, proteins and peptides are key important nutritional and bioactive molecular factors. The human milk proteome is continuously changing in composition throughout lactation, from colostrum to mature milk. For example, the overall protein content declines from $20 \mathrm{~g} / \mathrm{L}$ down to $10 \mathrm{~g} / \mathrm{L}$ and the whey/casein ratio shifts from $90 / 10$ to $60 / 40$ [2,4]. To gain deeper insights into the composition of human milk, personalized profiling offers unique opportunities, especially regarding the human milk proteome, encompassing both proteins and endogenous peptides. As human milk composition is donor-specific, personalized profiling strategies bring us closer to methodologies assisting individualized health care, taking into account a person's unique characteristics [5]. For human milk, this can lead to novel insights into the maternal-breastmilk-infant triad [6]. 
The human milk proteome is comprised of not only proteins, but also endogenous peptides derived from proteins upon proteolysis within the mammary gland. Many of these peptides are bioactive in their own regard and carry functions independent of their proteins of origin. These activities include antimicrobial, angiotensin converting enzyme (ACE) inhibition, dipeptidyl peptidase IV (DPP-IV) inhibition, opioid agonist and antagonist activities, immunomodulation, mineral binding, and antioxidative functions [7]. It is estimated that the endogenous peptidome contributes up to $2-3 \%$ of the total protein concentration [8-10]. The majority of human milk endogenous peptides are derived from abundant milk proteins_-such as caseins, osteopontin, and polymeric immunoglobulin receptor [11-15]. The main protein contributing to the peptidome is $\beta$-casein, making up approximately $50 \%$ of all endogenous peptides [11-15]. Therefore, it is critical to know the $\beta$-casein derived peptidome in detail, including how this may change dynamically over lactation, and how it is possibly modified by post-translational modifications (PTMs) such as phosphorylation and glycosylation, which may affect functionality. For the latter, it is also intriguing to know if such PTM features are distinctive between the proteome and peptidome.

$\beta$-casein is a 226 amino acid (including the signal peptide), $25 \mathrm{kDa}$ highly-phosphorylated protein. It makes up the majority of the casein micelle in human milk, followed by $\mathrm{k}$-casein and small amounts of $\alpha_{\mathrm{s} 1}$-casein. Structurally, a casein micelle consists of $\alpha_{\mathrm{s} 1}$-casein and $\beta$-casein forming an inner core, with $k$-casein making up the outer glycosylated layer that stabilizes the micelle, see Figure $1[16,17]$. The inner region of the casein micelle remains uncertain, resulting in an undetermined structure of $\beta$-casein. Even so, the lack of disulphide bridges suggests the protein is likely to not have a tightly defined secondary or tertiary structure, whereas the abundant prolines in the sequence predispose it to an open conformation [16]. This overall open structure makes the protein readily accessible to proteolytic cleavage. Plasminogen, its activators, and its inhibitors, are reported to be associated with the casein micelle and are predominantly responsible for $\beta$-casein degradation in the mammary gland, and thus for producing the putative bioactive peptides [18].

The main functions of casein proteins in human milk are to provide essential amino acids [19] and to bind and transport divalent cations, such as calcium and zinc, facilitating the absorption of these nutrients in the gut of the nursing infant [20]. The overall abundant phosphorylation of $\beta$-casein is thought to contribute to these functions. Moreover, there has also been antimicrobial functionality attributed to the $C$-terminal peptide derived from $\beta$ casein, (200QELLLNPTHQYPVTQPLAPVHNPISV ${ }_{226}$ ), in recent human milk peptidomics studies [14,21-26]. Additionally, this peptide has been found to survive infant digestion, indicating that it could exert antimicrobial functionality in the distal part of the infant gut [24]. Interestingly, all these studies use one source for justification of antimicrobial functionality of this peptide [27]. Namely, Minervini et al., tested the functionality of milk protein hydrolysates from six mammalian species and found that one particular hydrolyzed human milk sodium caseinate fraction containing the aforementioned peptide (and potential co-isolated variants thereof) showed considerable antimicrobial functionality against Escherichia coli (E. coli) F19 [27]. Very recently, the Minervini et al. results have been replicated by one group, which has published several studies confirming the antimicrobial functionality of various peptides across the C-terminus of $\beta$-casein [28-30].

Post-translational modifications (PTMs) are important regulators of proteins, often determining a protein's functionality. Phosphorylation is a widespread and critical PTM, and as such it is not surprising that $\beta$-casein exhibits differing functionality based on its varying degrees of abundant phosphorylation. Studies have shown that casein phosphorylation is critical for the formation of casein micelles and the subsequent delivery and absorption of calcium, phosphate and other minerals in the infant gut [31,32]. Additionally, protein glycosylation, one of the most prominent and complex PTMs of the human milk proteome, is also important when considering functionality. Glycosylation refers to the covalent attachment of oligosaccharides on the protein backbone as $\mathrm{N}$ - or $\mathrm{O}$-glycosylation. 
The most well-studied of these is $\mathrm{N}$-glycosylation, in which an oligosaccharide chain is attached to the protein via the amide group of an Asn residue within a defined sequon (Asn-Xxx-Thr/Ser, Xxx not being Pro) [33]. With O-glycosylation, the oligosaccharide chain is attached to the protein backbone via the oxygen of a hydroxylated amino acid, mainly Ser or Thr [34]. Importantly, it is estimated that up to $70 \%$ of the identified major abundant human milk proteins are glycosylated [35]. Notably, no glycosylation features have been reported so far for $\beta$-casein.

A

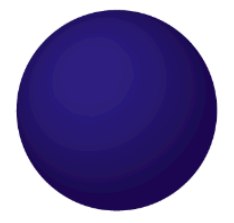

$\beta$-casein

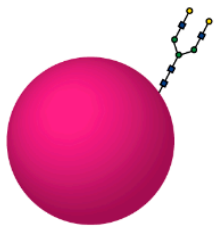

$\alpha_{\mathrm{s} 1}$-casein

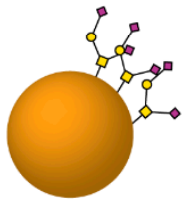

k-casein

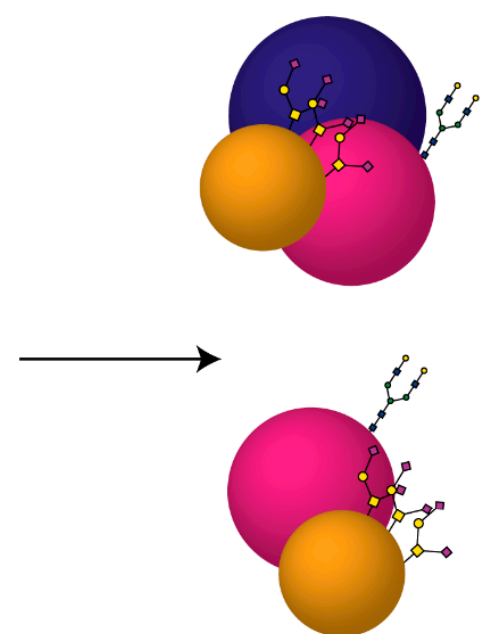

Submicelles
Calcium phosphate

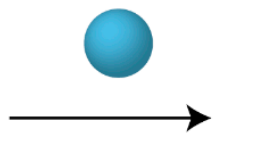

Micelle

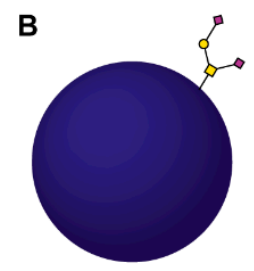

$\beta$-casein

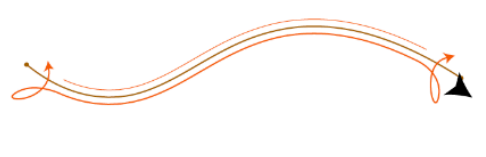

Unfolded

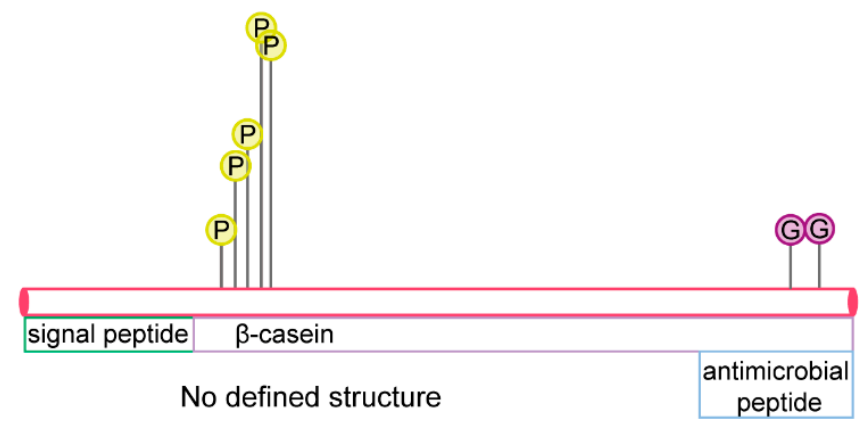

Figure 1. Proposed build-up of human milk casein micelles and proteoforms of casein proteins. (A) The three casein proteins in human milk, $\beta$-casein (dark purple), $\alpha$ S1-casein (magenta), and $\kappa$-casein (gold) are depicted according to their size and with known glycan structures annotated (as $\mathrm{N}$ - or $\mathrm{O}$-glycans). These together interact to form submicellar particles, which constitute the building blocks of the casein micelles held together by colloidal calcium phosphate nanoclusters (light blue). (B) Our novel observation of $\beta$-casein as an O-glycoprotein, depicted as a spherical and unfolded structure. Lollipop depictions of the PTMs identified are shown on the relative sequence of the protein, where P indicates a phosphorylated residue and $\mathrm{G}$ indicates the newly discovered $\mathrm{O}$-glycosylated residues; the height of the lollipop depictions is proportional to the relative abundances of the modifications identified on these sites.

The diversity and abundance of milk glycan species is important to consider, as these glycosylated compounds comprise free oligosaccharides, glycoproteins, glycopeptides, and glycolipids [36]. Moreover, these milk glycans are energetically costly for the mother to produce and predominantly indigestible by the infant, suggesting important alternative roles [37]. The delivery of these functional milk components changes throughout lactation to meet the developing needs of the infant, such as their innate immune system and gut 
microbiota. For instance, milk glycans work to shape the infant's intestinal ecology, binding or inhibiting binding of bacteria, viruses, and toxins to intestinal epithelial cells, enriching the gut microbiota with bifidobacteria, reducing inflammation, and promoting intestinal epithelial barrier function [37].

Recent advancements in analytical mass spectrometry have made it possible to characterize a variety of PTMs and how they dynamically change over time. Understanding this dynamic change is essential for gaining insights into the functionality of these proteins. Currently, there is a lack of understanding how dynamic protein changes affect the functionality of both the proteome and endogenous peptidome in human milk. We sought to investigate this in a protein specific manner for multiple PTMs in a longitudinal personalized profiling approach. We now show, for both the $\beta$-casein proteome and endogenous peptidome, how phosphorylation and O-glycosylation change over the first 16 weeks of lactation in two individual donors. In doing so, we have uncovered for the first time two $O$-glycosylation sites on the $C$-terminus of $\beta$-casein, in the peptide that has previously been shown to be antimicrobial.

\section{Results}

An initial in-depth proteomics screen of our data revealed evidence that the human milk protein $\beta$-casein seemingly harbored $O$-glycosylation modifications, in addition to being highly phosphorylated. As $O$-glycosylation has yet to be described for this protein, we focused on characterizing $\beta$-casein as a novel $O$-glycoprotein with distinct glycan modifications in the intact protein and in the endogenous $O$-glycopeptidome. Longitudinal personalized profiling was performed to detect human milk peptides carrying O-glycans, wherein milk from two individual donors was assessed for both the proteome and peptidome. The overall experimental workflow is depicted in Supplemental Figure S1. In brief, milk samples were collected longitudinally from two mothers across colostrum $(<72 \mathrm{~h})$, transitional ( $>3-15$ days), and mature ( $>16$ days) lactational stages [38-40], i.e., at weeks $1,2,3,4,6,8,10,12$, and 16. Standard protein and endogenous peptide extraction methods were applied as described before [41], and samples were analyzed by label-free shotgun glycoproteomics and glycopeptidomics approaches.

Typically, to analyze glycopeptides, one first enriches them from the large pool of nonmodified peptides. However, here we show that making use of advances in MS, namely hybrid fragmentation approaches such as HCD-pd-sHCD and HCD-pd-EThcD, large-scale characterization of thousands of intact glycopeptides is feasible [42-44], even from highly complex samples such as human milk. In this work, we focused our analysis on $\beta$-casein, with the aim to get a comprehensive view of all its proteoforms and endogenous peptide modifications. $\beta$-casein is an important and ideal protein candidate to investigate these PTMs at the proteome and peptidome level, as it makes up a large percentage of both. In terms of abundance, $65 \%$ of the endogenous peptidome originated from caseins $\left(\alpha_{\mathrm{s} 1}-, \beta_{-}\right.$, and $\mathrm{k}-$ ), with $\beta$-casein making up $50 \%$ of the total peptidome, while in the proteome the caseins only made up about $30 \%$ of total protein abundance [41].

\subsection{Mass Analysis of Intact $\beta$-Casein Proteoforms}

Initially, intact protein mass spectrometry was performed to evaluate the scope of all $\beta$-casein proteoforms in human milk. From this analysis we were able to annotate a total of $16 \beta$-casein proteoforms. These included the six previously described phosphoproteoforms-i.e., $\beta$-casein $0-5 \mathrm{P}$ - and ten newly-detected glycoproteoforms (Supplemental Table S1). Figure 2 depicts the deconvoluted mass spectra of the $\beta$-casein proteoforms detected in the whole milk of donor 2 . While all $\beta$-casein phosphoproteoforms in the range of $0-5 \mathrm{P}$ could be detected, the $2 \mathrm{P}$ and $4 \mathrm{P}$ forms were most abundant. This is in line with previous studies that also found $2 \mathrm{P}$ and $4 \mathrm{P}$ to be the most abundant of the six known $\beta$-casein proteoforms $[45,46]$. Phosphosite occupancy could potentially affect the ability $\beta$-casein to bind calcium. We observed a decrease of phosphosite occupancy over lactation for both donors, both in the proteome and in the endogenous peptidome. 
According to Neville et al. (1994), the total calcium content of human milk decreased during lactation, with the absolute concentration of the soluble calcium remaining stable [47]. This strongly indicates that particularly the protein-bound calcium, rather than total calcium, decreased. This is line with a decrease in the capacity of $\beta$-casein to bind calcium, possibly due to the decrease in the degree of its phosphorylation across lactation. We observed an overall decline in phosphorylation across lactation as well, Figure 2.

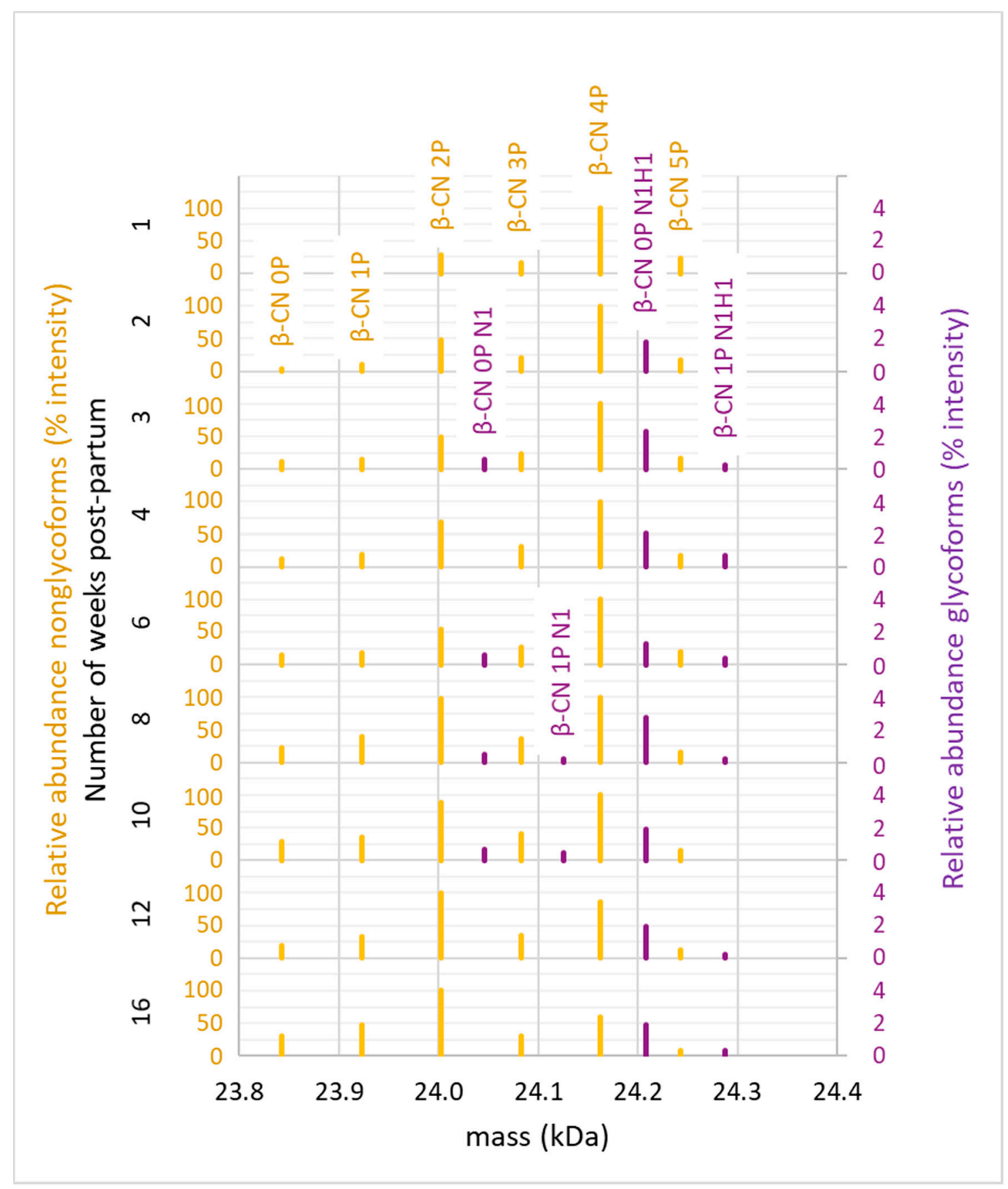

Figure 2. Deconvoluted mass spectra depicting the $\beta$-casein proteoforms identified in the whole milk of donor two throughout lactation. The non-glycosylated proteoforms (yellow) comprised phosphorylation in the range of $0-5 \mathrm{P}$ and were confirmed by database search of the intact protein LC-MS/MS results. Minor glycosylated proteoforms ( $\sim-4 \%$ relative abundance of the most abundant $\beta$-casein proteoform; purple) could be annotated in the intact protein LC-MS data by the mass shift induced by the glycan residue masses. 
The glycoproteoforms were detected as minor constituents and were identified by mass differences of the non-glycosylated proteoforms and corresponding glycan residues. Glycoproteoforms of the 0 and $1 \mathrm{P}$ forms of $\beta$-casein can be observed and the mass differences in this case could be matched to the glycan masses of $\mathrm{N}_{1}$ and $\mathrm{N}_{1} \mathrm{H}_{1}$ in the minor proteoforms depicted across lactation in Figure $2(\mathrm{~F}=$ deoxyhexose, $\mathrm{H}=$ hexose, $\mathrm{N}=\mathrm{N}$-acetylhexosamine, $\mathrm{S}=\mathrm{N}$-acetylneuraminic acid). The presence of minor glycoproteoforms was confirmed in both donors across lactation (Figure 2, data only depicted for donor two), revealing unambiguously that $\beta$-casein is not only a phosphoprotein, but also a glycoprotein. For further confirmation of $\beta$-casein glycosylation and for PTM site localization the samples were next analyzed by bottom-up LC-MS/MS.

\subsection{Data Analysis Strategy for Bottom-Up Mass Spectrometry}

Using a bottom-up mass spectrometry approach, we identified a total of 44,667 nonmodified and 2286 glycosylated $\beta$-casein peptide-to-spectrum matches (PSMs, a measure of correctly annotated spectra) from the proteome data, and 48,295 non-modified and 2241 glycosylated from the peptidome data. These metrics are from accumulated data for both donors and all time points after data curation presented in Supplemental Table S2. After strict filtering criteria, an average of 5 percent of all PSMs, coming from both donors across all time points, could be attributed to glycosylation in the proteome and peptidome, 2286 and 2241 PSMs, respectively. Curation criteria were selected to reduce potentially false PSMs, determined by the count of reverse sequences identified by Byonic.

The first step in the curation criteria was to remove PSMs from the signal peptide, amino acids 1-15, leaving only PSMs generated from the mature protein. Second, only PSMs matched to spectra of non-negligible error probabilities were accepted, i.e., $\mid \log$ Prob $\mid \geq 1.5$, Byonic score $\geq 150$ and Delta Mod score $>5$. Next, we used the number of PSMs as a proxy for the abundance of the given PTMs in the proteome and peptidome data. One can argue that highly abundant PTMs, compared to those with lower abundance, will have increased chromatography elution time widths, more charge states that can be detected, more structural isomers that can be measured separately, a higher chance of triggering MS2, an improved chance of identification by a search engine, and importantly, it will be detected on more low-abundance peptide variants. While the absolute number of detected PSMs cannot be directly compared between the proteome and peptidome datasets, within each dataset the observed trends and relative occupancy ratios are expected to be representative.

After applying strict automatic filtering criteria, we additionally inspected each potential phospho- and glycosite for the presence of the correct peptide fragments and fragments corresponding to phosphorylation and/or glycosylation. All automatically annotated glycosites on the N-terminus of the protein were found to lack supportive fragmentation evidence and were excluded from further analysis. We show in Supplemental Figure S2 (donor one, week 16, EThcD) the negative characteristics of spectra that were not included in the final interpretation of glycopeptide PSMs. Negative characteristics included the following: abundant peaks without annotation, nonsensical or high numbers of glycan species that are not supported by fragment series (e.g., more than triply glycosylated, but without corresponding oxonium ions) and an absence of peptide fragments with retained modifications (either for glycosylation or phosphorylation).

\section{3. $\beta$-Casein Phosphorylation Analysis}

The total PTM PSMs for both phosphorylation and glycosylation were found to be variable between the two donors and across lactation (Supplemental Table S3). We identified confidently five phosphosites (Ser/Thr) spanning the N-terminal peptide ${ }_{16}$ RETIESLSSSEESIT $_{30}$, with the detected phosphorylation sites in bold (Figure 3, Supplemental Figure S3). In accordance with previous literature $[31,45,46,48-50]$, we found this N-terminal phosphorylation cluster to have up to all five of the aforementioned phosphosites occupied with varying degrees of stoichiometry between donors, across lactation, and relative to the proteome or peptidome 
(Figure 4). Overall, site Ser24 showed the highest number of PSMs (e.g., the mean phosphosite PSMs across all time points being 197 and 663 for respectively the proteome and peptidome for donor one), followed by Ser25, Ser23, Ser21, and Thr18 regardless of the donor, lactational stage, proteome or peptidome data (Figure 4, Supplemental Figure S4 and Supplemental Table S3). This overall observed trend in phosphosite occupancy is in line with literature data [48,51]. The identified phosphosites follow the Ser/Thr-Xxx-Glu/pSer sequence motif recognized by the FAM20C kinase, which has been identified as the Golgi casein kinase responsible for this phosphorylation [52,53]. Accordingly, Ser24 and Ser25, also fitting this motif, were found to be the most highly phosphorylated $(\sim 70-85 \%$ per site). These two phosphosites also displayed differing degrees of phosphorylation across lactation and between the proteome and the endogenous peptidome. For instance, in the proteome and the peptidome, sites Ser24 and Ser25 were observed to have site occupancies of $>90 \%$ at early lactation, with a gradual decline to $65 \%$ at later stages of lactation (Figure 4). However, the number of occupied phosphosites differed between the peptidome and the proteome, with respectively $4-5$ and 2-3 phosphosites occupied at any given time, indicating that $\beta$-casein endogenous peptides were generally more phosphorylated than the $\beta$-casein protein (Figure 4). Additionally, there was a high degree of individual variability in the degree of phosphosite occupancy between donors across lactation. For instance, in the peptidome, donor one had the highest phosphosite occupancy on sites Ser24 (mean $85 \%$ ) and Ser25 (mean $84 \%$ ) at any given time, compared to donor two Ser24 (mean $72 \%$ ) and Ser 25 (mean $70 \%$ ). However, the dynamic change in site occupancy was less dramatic over lactation in donor one than donor two, only changing by $17 \%$ in donor one versus up to $34 \%$ in donor two, Supplemental Table S4. Similar trends were also observed in the proteome indicating that phosphosite occupancies can be donor-dependent.

While the N-terminal stretch of $\beta$-casein is heavily decorated by several phosphorylations, we found no convincing evidence of phosphorylation occurring on any other Ser or Thr residues in the protein sequence in both the proteome and the peptidome data (Figure 4, Supplemental Tables S3 and S4). This is in accordance with the fact that no other Ser or Thr residues in the amino acid sequence of the protein are found to fit the FAM20C phosphorylation motif.

\section{4. $\beta$-Casein Glycosylation Analysis}

We found convincing evidence that the $C$-terminal stretch of $\beta$-casein contained $O$-glycans, both in the proteome and peptidome data. As this finding is novel, and $O$-glycosylation quite difficult to annotate, we recorded $O$-glycopeptide fragmentation by EThcD, as this provides often more confident assignments [54]. An illustrative set of annotated EThcD spectra, spanning the C-terminal ladder peptide (197 LLNQELLLNPTHQYPVTQPLAPVHNPISV $_{226}$ ), are depicted in Figure 5, illustrating fragment ions indicative of the peptide backbone, carrying small neutral, sialylated, and fucosylated $O$-glycan species. Predominantly, in both the proteome and peptidome data, the sites Thr207 and Thr214 were found to be occupied by a variety of several different $O$-glycan species (Figure 6, Supplemental Table S5). For donor one specifically, across all time points for Thr207 and Thr214 we identified a total of 813 (mean 90, 12\% occupancy) and 1082 (mean 120, 17\% occupancy) O-glycopeptide PSMs in the proteome and 619 (mean 69, 12\% occupancy) and 852 (mean 95, 17\% occupancy) O-glycopeptide PSMs in the peptidome (Figure 4, Supplemental Figure S4, Supplemental Tables S3 and S4). For donor two, across all time points for Thr207 and Thr214 we identify a total of 465 (mean 52, 10\% occupancy) and 709 (mean 79, 16\% occupancy) O-glycopeptide PSMs in the proteome and 546 (mean 61,13\% occupancy) and 723 (mean 80, 17\% occupancy) O-glycopeptide PSMs in the peptidome (Figure 4, Supplemental Figure S4, Supplemental Tables S3 and S4). 


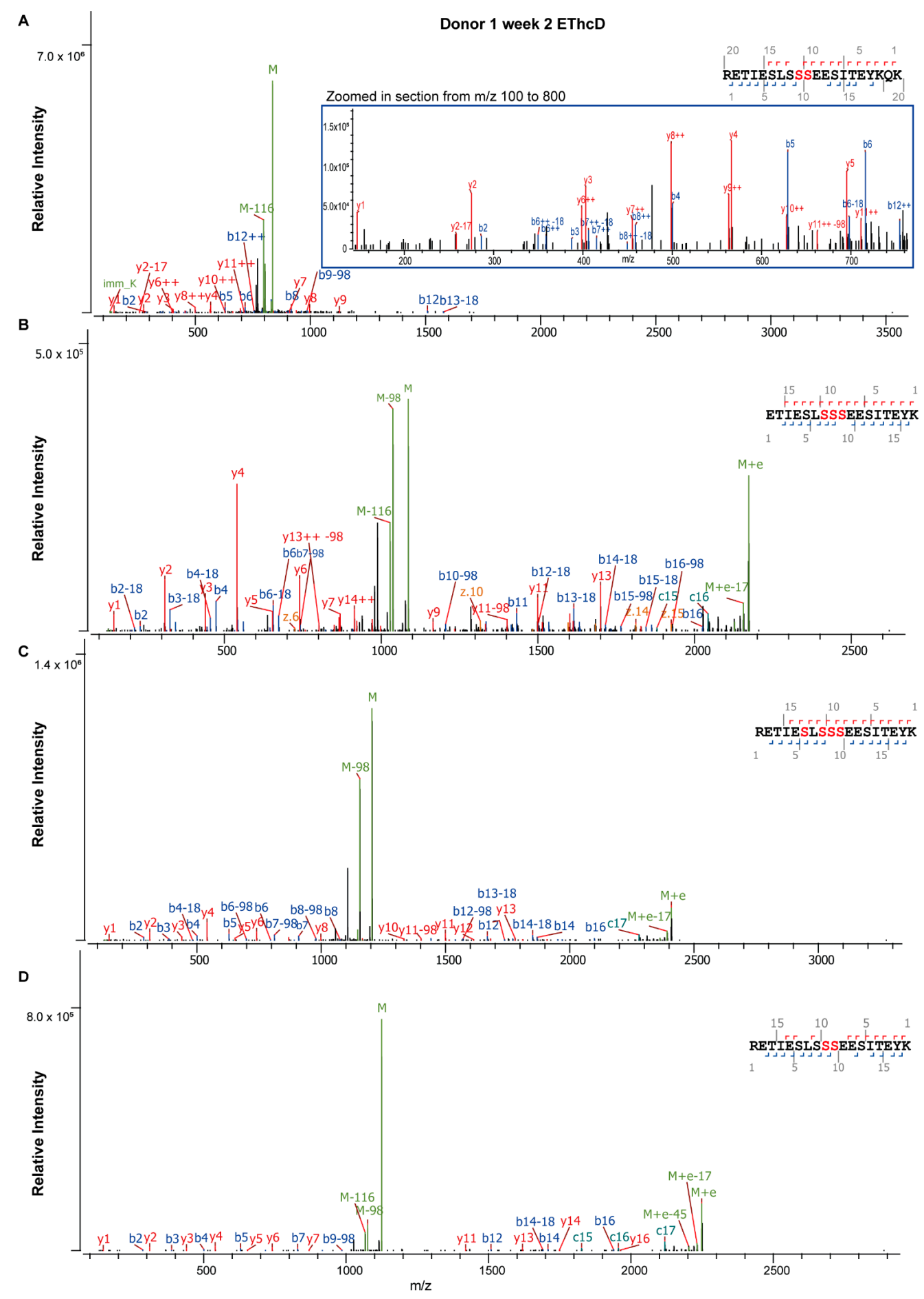

Figure 3. Illustrative EThcD fragmentation spectra of $\beta$-casein phosphopeptides. The N-terminal peptide ${ }_{16}$ RETIESLSSSEESIT $_{30}$ with up to seven phosphosites is depicted with varying degrees of site occupancy in the peptidome (A-C) and proteome (D). Designated phosphosites are indicated as red amino acids in the peptide sequence. Confidence in the phosphosite annotations are evident from the precursor mass with the neutral loss of phosphorylation from Ser (M-98 Da) upon fragmentation, with additional b- and y-ions from the peptide backbone placing the -98 Da at specific Ser residues. (A) Peptidome phosphopeptide harboring two phosphorylated Ser residues, the inset of $m / z$ 100-800 shows the b- and y-ion series that might otherwise be obscured by the intensity of the other ions. (B) Peptidome peptide with three phosphorylated Ser residues. (C) Peptidome peptide with four phosphorylated Ser residues. (D) Proteome peptide with two phosphorylated Ser residues. 
A
Donor one

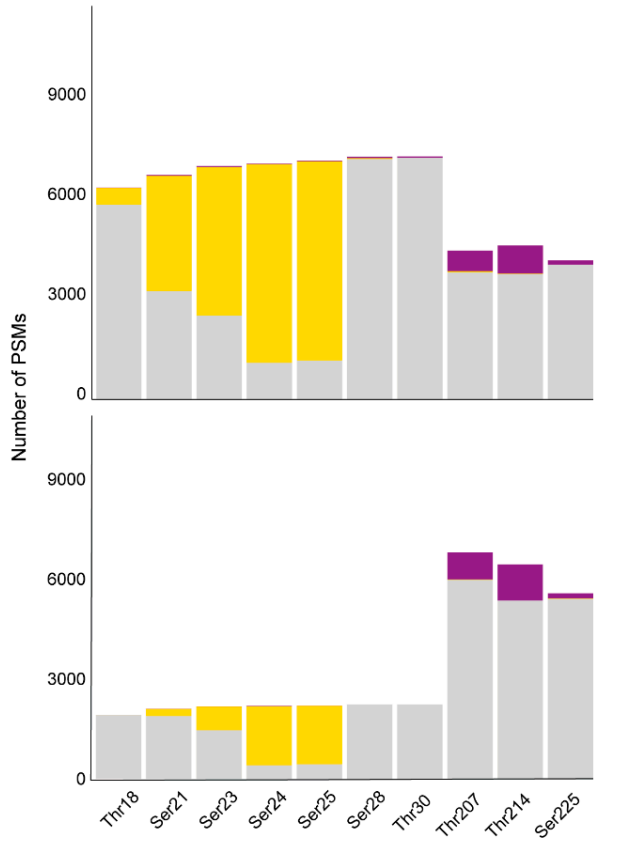

Donor two
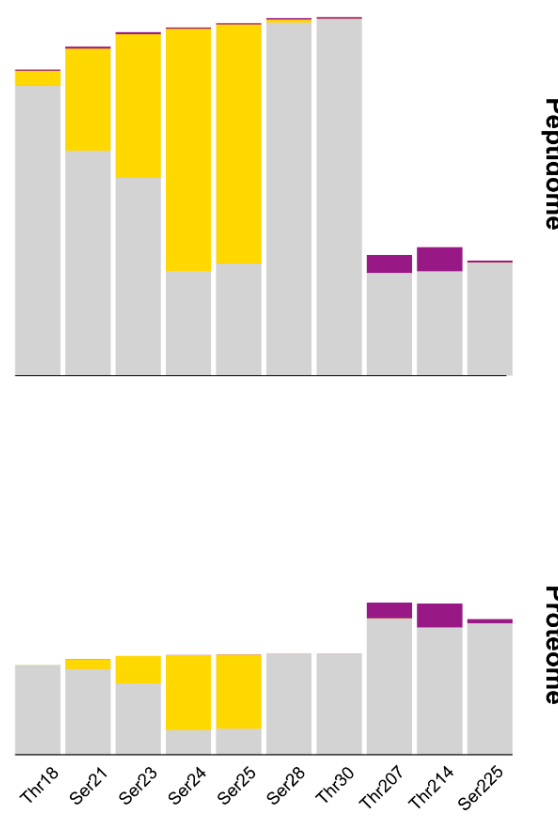

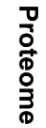

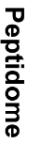

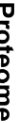

B

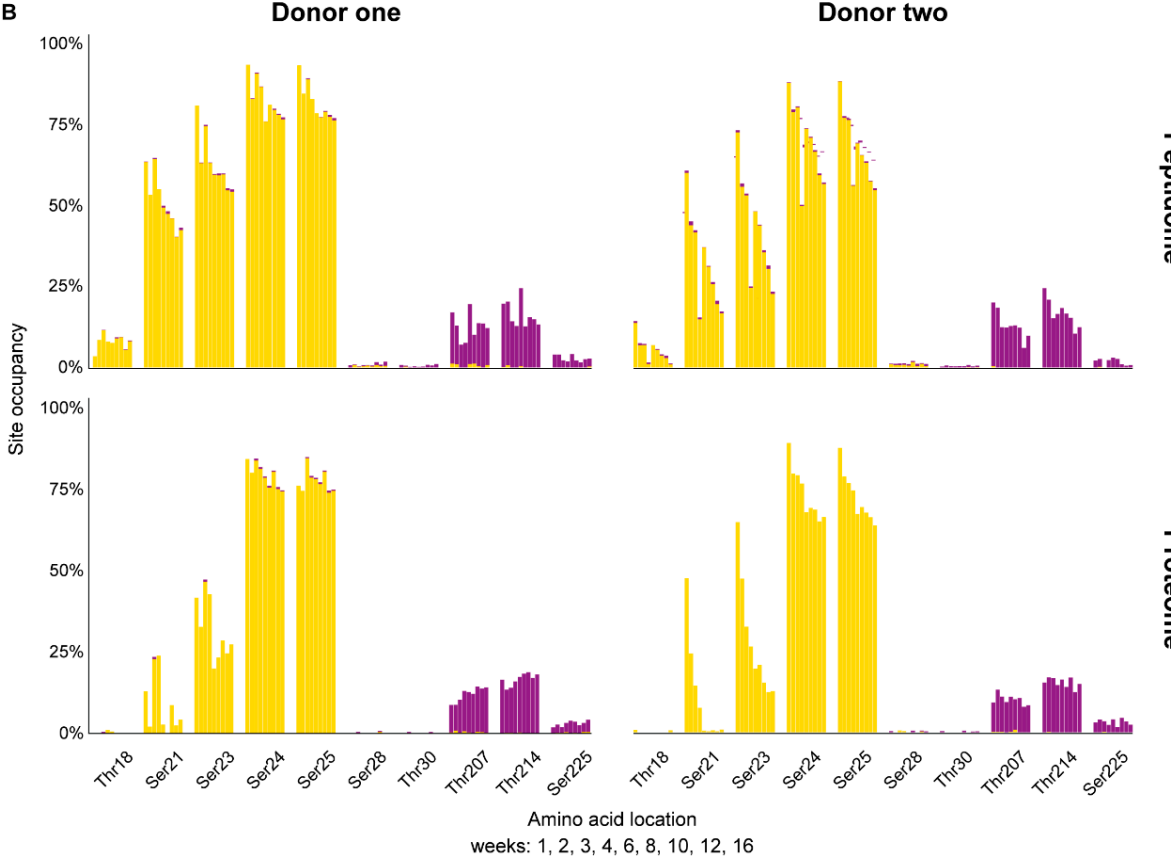

Figure 4. Semi-quantitative analysis of phosphorylated and glycosylated amino acids detected in $\beta$-casein across lactation. (A) Total number of detections of Thr18, Ser21, Ser23, Ser24, Ser25, Ser28, Thr30, Thr208, Thr214, and Ser225 for each donor in either the peptidome and proteome, colored for the presence of phosphorylation (yellow), glycosylation (purple), or without modifications (grey). (B) Percentage of modified amino acids amongst the total number of detections, separately displayed for lactation weeks 1, 2, 3, 4, 6, 8, 10, 12, and 16. While the observed PTMs are donor-specific, overall, the peptidome data displays a greater relative abundance of phosphorylated and glycosylated sites than the proteome data, and highly similar changes can be seen across lactation for both donors. Whereas all phosphorylation sites are near the $\mathrm{N}$-terminus, the $\mathrm{O}$-glycosylation sites are all at the $\mathrm{C}$-terminus of $\beta$-casein. 
A

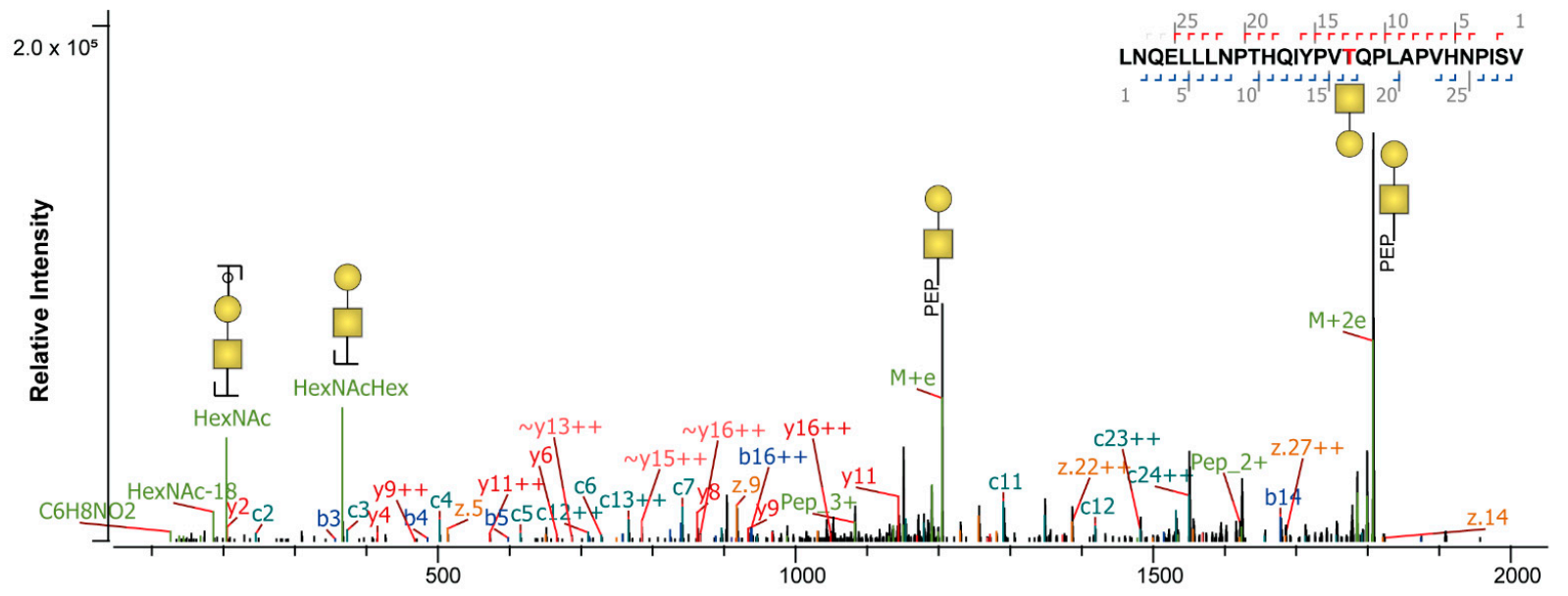

B

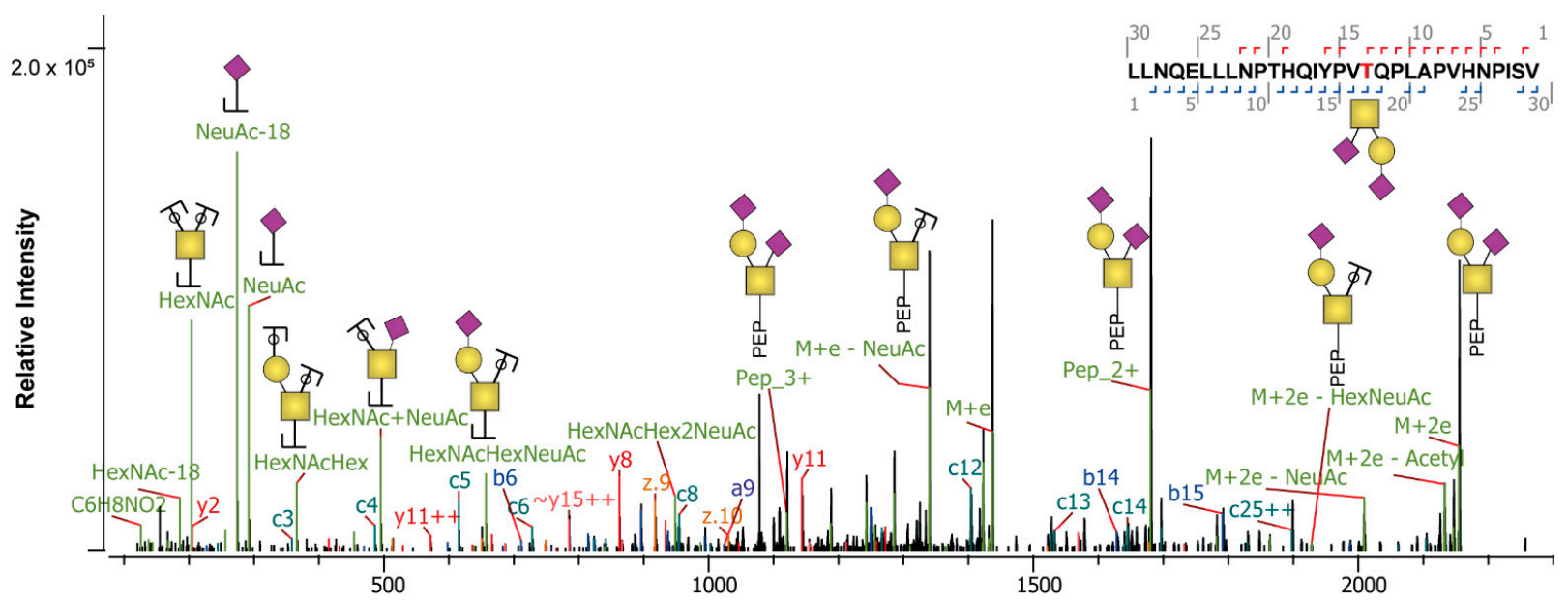

C

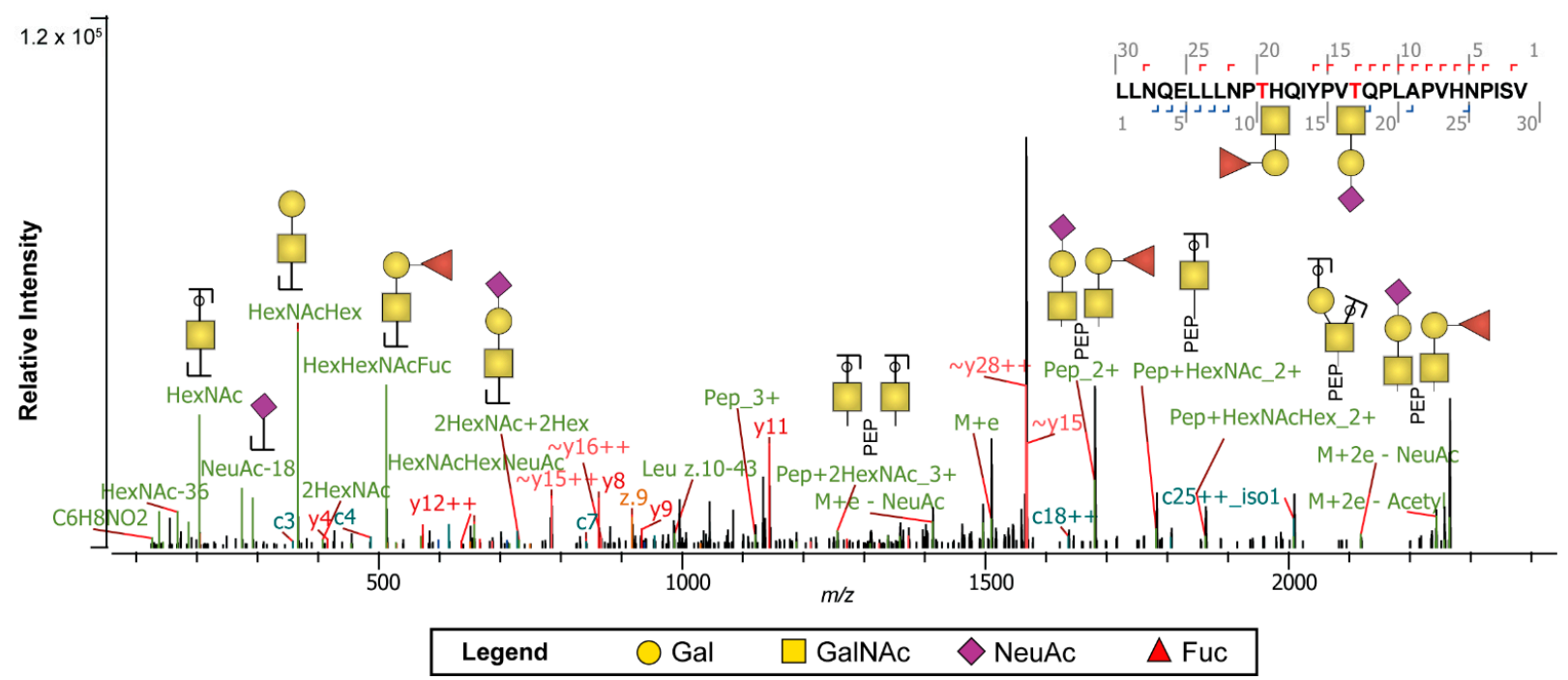

Figure 5. EThcD fragmentation spectra of the C-terminal $\beta$-casein peptide ${ }_{197}$ LLNQELLLNPTHQYPVTQPLAPVHNPISV $_{226}$ decorated by distinct $O$-glycans. (A) EThcD spectra with the $O$-glycopeptide carrying $\mathrm{N}_{1} \mathrm{H}_{1}$ glycosylation. (B) EThcD spectra with the $O$-glycopeptide carrying a sialylated glycan, $\mathrm{N}_{1} \mathrm{H}_{1} \mathrm{~S}_{2}$. (C) EThcD spectra with the O-glycopeptide carrying sialylated and fucosylated glycans, $\mathrm{N}_{1} \mathrm{H}_{1} \mathrm{~S}_{1}$ and $\mathrm{N}_{1} \mathrm{H}_{1} \mathrm{~F}_{1}$. Note that a mixture of positional isomers could have been fragmented in the presented spectra and that different glycan structures likely exist for the displayed annotations. Only major glycan fragments are annotated. The monosaccharide legend is displayed at the bottom. 

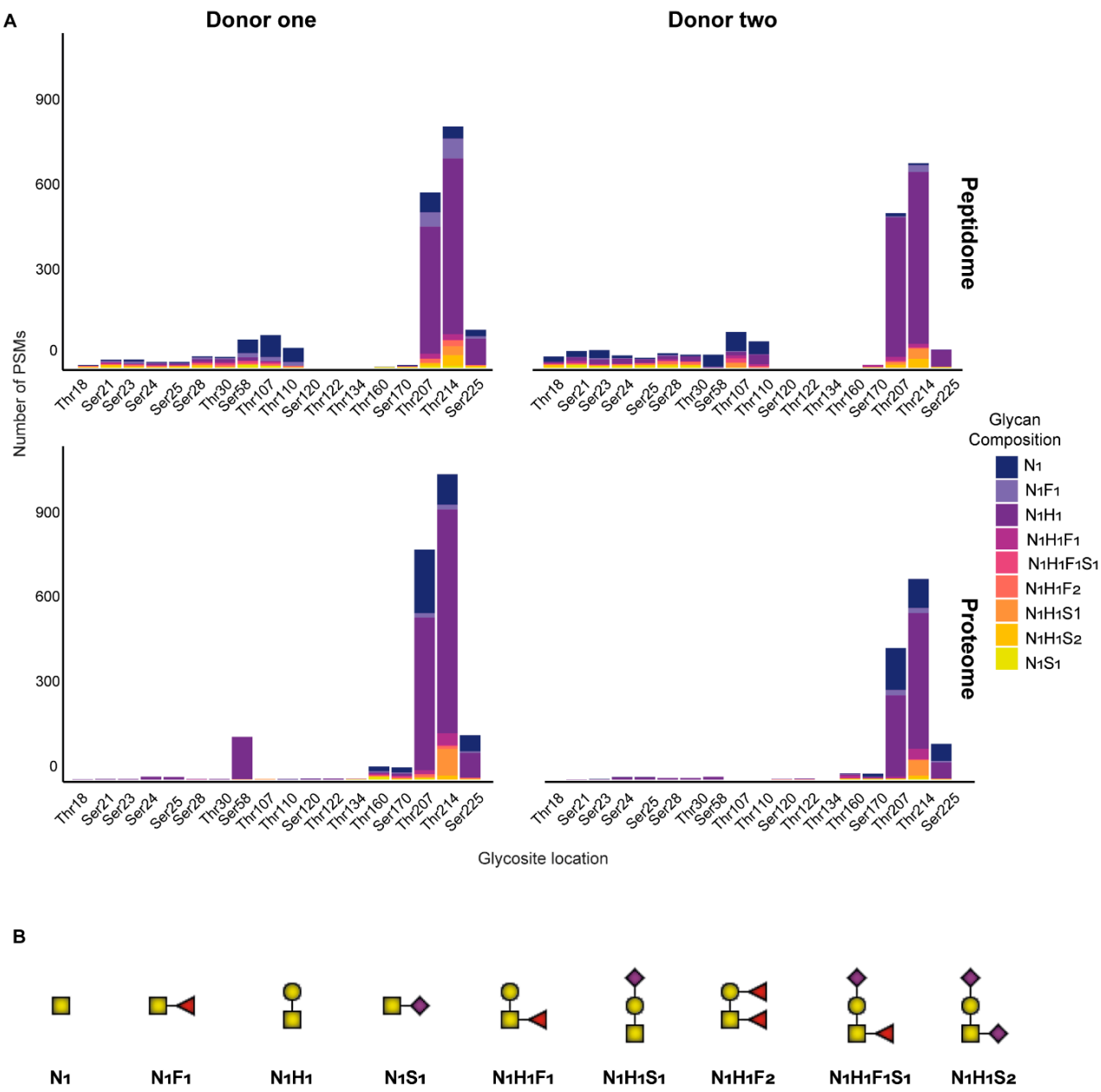

Figure 6. Site analysis of glycan species identified across the peptidome and proteome in each of the donors. (A) The glycan species are displayed for the peptidome and proteome at all possible Ser and Thr sites across the protein backbone for donors one and two. Glycan species are displayed as stacked bars of PSMs per site, with each glycan species represented with a different color. The sites Thr207 and Thr214 in the peptidome and proteome have the highest number of O-glyco-PSMs and are occupied by primarily $\mathrm{N}_{1}$ and $\mathrm{N}_{1} \mathrm{H}_{1}$ glycans. (B) Schematic representations of the nine different $O$-glycans identified on human $\beta$-casein. Our MS method did not distinguish structural elements of the glycosylation, and the representations only inform on the composition of the glycan species.

Notably, the stoichiometry of glycosylation changed throughout lactation, a feature even more intense in the peptidome than the proteome. For instance, for both donors in the proteome, glycosite occupancy remained rather consistent, with Thr207 at $10 \%$ and Thr214 at 16\% (Supplemental Table S4). However, for both donors in the peptidome, there was a clear declining trend in these site occupancies over lactation. An exception to this trend was observed in donor one at week 6 which had site occupancies spike back to the values observed at week 1 . This aberrant milk composition at one point in time from donor one corresponded to a potential maternal infection, as previously reported in detail [41]. Interestingly, the glycans occupying these two sites are predominantly made up of three species- $\mathrm{N}_{1} \mathrm{H}_{1}, \mathrm{~N}_{1}$, and $\mathrm{N}_{1} \mathrm{~F}_{1}$ (in order of highest to lowest PSM counts) - regardless of being identified in the proteome or peptidome Figure 6.

Although quantification using PSMs showed distinct trends between donors and across time, we aimed to further validate our $O$-glycan quantification by comparing precursor ion MS1 areas using Skyline $[55,56]$. The MS1 integration indicated that, in both the proteome and the peptidome data, glycopeptide masses could be detected that were comparative with Byonic's assignment of one and two occupied glycosylation sites (Figure 7, Supplemental Figure S5, and Supplemental Table S5). Furthermore, the MS1 integration verified 
an overall approximate $5 \%$ glycosylation occupancy, in line with the fragmentation data derived by Byonic. It also supported that the most abundant $O$-glycosylation occurred at early lactation and gradually declined over time. This change could be seen for multiple ladder peptides ranging from ${ }_{190}$ AVPVQALLLNQELLLNPTHQIYPVTQPLAPVHNPISV 226 to ${ }_{200}$ QELLLNPTHQIYPVTQPLAPVHNPISV $_{226}$ (Figure 7, Supplemental Figure S5 and Supplemental Table S5). Overall, MS1 area integration yielded highly comparable trends with PSM-based quantification (Supplemental Table S6), with early lactation resulting in more overall glycosylation than later lactation. Indicating that both analysis strategies were viable to use for judging $O$-glycan occupancy on $\beta$-casein.
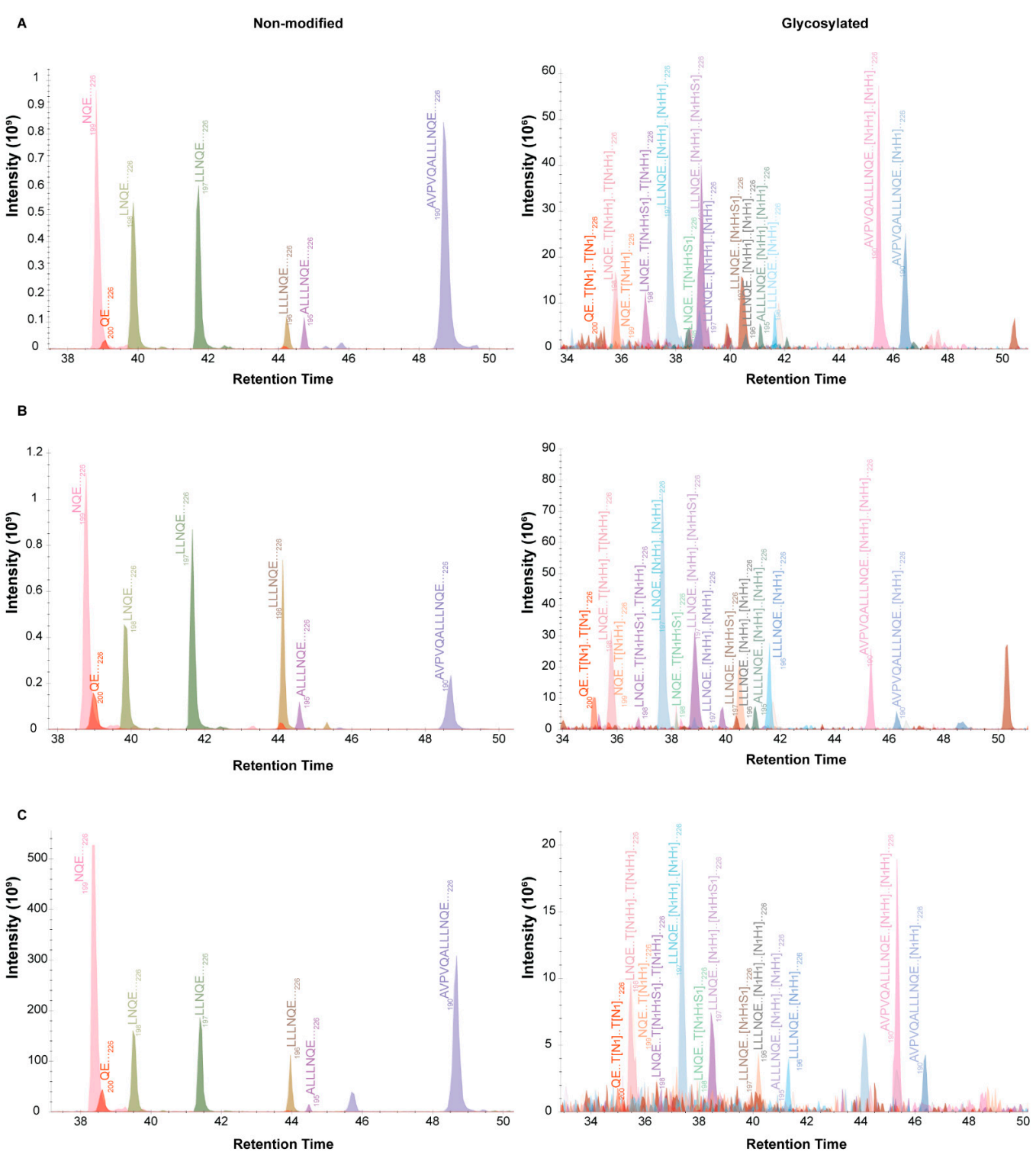

Figure 7. Changes in abundances of O-glycosylated peptide variants during early and late lactation. All presented ion traces originate from donor one and show the C-terminal $\beta$-casein ladder peptide series beginning with ${ }_{190}$ AVPVQALLLNQ ELLLNPTHQIYPVTQPLAPVHNPISV 226 and ending with the antimicrobial peptide ${ }_{200}$ QELLLNPTHQYPVTQPLAPVHNPISV $_{226}$. All ladder peptides are decorated by different $O$-glycan species, as containing a single glycan on Thr207 or Thr214, or having both sites occupied. All ladder peptides were found decorated with $\mathrm{N}_{1}, \mathrm{~N}_{1} \mathrm{H}_{1}$ or $\mathrm{N}_{1} \mathrm{H}_{1} \mathrm{~S}_{1}$ glycan species. Precursor ion traces are depicted as non-modified (left) and glycosylated (right). (A) MS1 traces of the differing glycopeptides relative to the non-modified peptide in week 1. (B) MS1 traces of the differing glycopeptides relative to the non-modified peptide in week 6. (C) MS1 traces of the differing glycopeptides relative to the non-modified peptide in week 16 . 
We could also trace back non-modified ladder peptides spanning this sequence, from ${ }_{200}$ QELLLNPTHQYPVTQPLAPVHNPISV 226 down to ${ }_{218}$ APVHNPISV $_{226}$ (Supplemental Figure S6). All of these peptides spanning the same sequence exhibited different concentrations and distinctive trends in abundance between donors and across lactation. Although currently not known, all these peptides may have variable biological activity. Like the bottom-up site occupancy data, again donor one week 6 becomes an interesting time point, where the MS1 data for the reported antimicrobial peptide does not follow a clear lactational trend. Rather, at this aberrant time point, this supposed antimicrobial peptide, and many of the other ladder peptides, on average goes substantially up relative to all other time points (Supplemental Table S5).

\section{Discussion}

The overall analysis of PTMs in complex biofluids by mass spectrometry is challenging due to the high dynamic range of proteins, overall low abundance of peptides with PTMs relative to non-modified peptides, and potential ion suppression of modified peptides. To overcome these challenges sample preparation methods have focused on enriching for a particular PTM of interest, such as phosphorylation or $\mathrm{N}$-glycosylation. This in turn limits the analysis to these chosen PTMs, not allowing a full proteome-wide approach, but rather requiring the analysis of the proteome and the enriched PTM fraction of the proteome in parallel. Even with this approach, one is usually limited to the most abundant proteins in a given sample. There have been steps to implement these advances in the analysis of human milk PTMs such as phosphorylation [48] and N-glycosylation [57,58] over the course of lactation, showing the dynamic variability of these PTMs over time. Even with these advancements, additional PTMs such as O-glycosylation have thus far been largely neglected. However, recent advancements in mass spectrometry now enable the analysis of these PTMs simultaneously without prior sample enrichment. From two donors over the first 16 weeks of lactation, we observed gradual temporal changes in the total PSM counts of phosphorylated and $O$-glycosylated peptides on both the protein $\beta$-casein and its endogenous peptidome. Interestingly, the endogenous peptidome consisted overall of more phospho- and O-glycopeptides than the proteome, indicating that PTMs may contribute to a rich source of functional endogenous peptides that has received limited attention.

\subsection{Phosphorylation Differences between $\beta$-Casein and Its Peptidome}

The degree of phosphorylation on $\beta$-casein not only regulates the size of the casein micelle, it also influences the function of the protein [31,51,59]. This, in turn, affects the overall digestibility, release, and absorption of functional proteins and peptides in the infant intestinal tract. The phosphosites of human milk caseins have been extensively studied [31,48-50] and even the site occupancy over the first month of lactation has been well-characterized in terms of the intact protein [48], but work on the peptidome has lagged behind. Previous studies have shown that the preferred phosphorylation order is Ser24 > Ser25 > Ser23 > Ser21 > Thr18, with a preference for four sites being occupied at any given time throughout lactation [48,51]. Our data are in line with these reports regarding the preferential order of phosphosites, but our data suggests that occupancy of more than three phosphosites predominantly occurs on the endogenous peptides and not the intact protein. Even in the proteome data we found that the third phosphosite was only occupied about $29-33 \%$ of the time, whereas in the peptidome it was likely that four phosphosites were occupied at least $33-53 \%$ of the time.

The degree of phosphorylation of $\beta$-casein is known to directly affect its function. For instance, different phosphoproteoforms are better at inhibiting $H$. influenzae than others [51]. This study found that the most common phosphoproteoforms of $\beta$-casein, by concentration, were tetra- $>$ di- $>$ non- $>$ mono- $>$ tri- $>$ penta-phosphorylated. Furthermore, they found that in an anti-adhesion assay, the tri-, tetra-, and penta-phosphorylated forms of $\beta$-casein exhibited more than $60 \%$ inhibition of $H$. influenzae [51]. Other effects of phosphorylation functionality have been less well-studied; for instance, how the differing 
degrees of phosphorylation of $\beta$-casein affect casein peptide release both in the mammary gland and in the infant's stomach. Currently, there is little evidence on endogenous phosphopeptidoforms and their bioactive functions, and the data provided here for $\beta$ casein may prove useful for future functional characterization.

\subsection{O-Glycosylation Changes Across Lactation in the $\beta$-Casein Protein and Its Peptidome}

We report here, for the first time, the presence of $O$-glycans on $\beta$-casein, in particular on the C-terminal stretch at sites Thr207 and Thr214. We observed individual specific and longitudinal dynamic changes in the site occupancy of $O$-glycosylation across the proteome as well as the peptidome data. Even with these dynamic differences, consistently both Thr207 and Thr214 contained O-glycans. The most dominant detected glycan moieties were $\mathrm{N}_{1} \mathrm{H}_{1}$. However, the second most abundant glycan species seems to be different between the intact protein and endogenous peptides, irrespective of donor or lactational stage, in which the proteome data contained more $\mathrm{N}_{1}$ glycans, and the peptidome data had substantially more $\mathrm{N}_{1} \mathrm{~F}_{1}$ glycans. The individual specific nature of human milk glycosylation has been previously observed in $\mathrm{N}$-glycoproteomics studies as well [57,58].

Our finding of $O$-glycans on the $C$-terminal stretch of $\beta$-casein is important in the context of the work by Minervini et al., which determined that the C-terminal $\beta$-casein derived peptide ( ${ }_{200}$ QELLLNPTHQIYPVTQPLAPVHNPISV ${ }_{226}$ ) has antimicrobial functionality [27]. Minervini et al. generated this peptide by preparing sodium caseinate from human milk and subsequently hydrolyzing it with the Lactobacillus helveticus PR4 proteinase. The purified peptide fraction was found to exhibit biological antimicrobial activity. It is highly probable that the glycosylated forms of the peptide were unknowingly co-enriched and contributed to the observed bioactivity. While the work of Minervini et al. focused on the unique peptide generated by the specific Lactobacillus helveticus PR4 proteinase, another group has recently published on several ladder series peptides related to the initially reported antimicrobial peptide, ${ }_{200}$ QELLLNPTHQIYPVTQPLAPVHNPISV 226 , for which activities were tested in cell culture assays against varying bacterial species with synthetic (non-modified) peptides. Specifically, peptides derived from the C-terminal part of $\beta$-casein were found to have antimicrobial functionality against specific bacterial species: peptides 201-220 and 213-226 had activity against S. aureus and Y. enterocolitica [28,29]; peptide 211-225 had activity against E. coli and Y. enterocolitica [30]. Interestingly, in all of these studies, the varying ladder peptides showed the same mode of antimicrobial activity, by membrane disrupting mechanisms, but not by binding to intracellular nucleic acids. While these studies used concentration ranges consistent with our own data, $0.5-20 \mu \mathrm{g} / \mathrm{mL}$, we only observe higher concentrations during the first two weeks of lactation and again in donor one at week 6, which relates to a suspected period of infection [41]. Furthermore, these studies indicate that not only the specific peptide reported by Minervini et al., but in fact a series of C-terminal ladder peptides as also detected in our study are all biologically active. Therefore, it is reasonable to assume that adding $O$-glycosylation to the C-terminal ladder series of peptides from $\beta$-casein may influence their bactericidal activity. Therefore, while synthesis of $O$-glycosylated peptide standards is still a major challenge such antimicrobial assays should ideally take into account the here-reported $O$-glycosylation features.

\section{Materials and Methods}

\subsection{Human Subjects and Milk Samples}

Details of subjects, bottom-up proteomics, and mass spectrometry (MS) methods have been described in detail before [41]. Longitudinal human milk samples were collected from two healthy donors at weeks 1, 2, 3, 4, 6, 8, 10, 12, and 16 postpartum. Samples were collected according to standardized human milk handling conditions [60]. All samples were collected into $2 \mathrm{~mL}$ Eppendorf tubes containing protease and phosphatase inhibitors as $1 / 9$ of the collection volume, Complete Mini EDTA-free (Roche) and PhosSTOP (Roche), respectively. Samples were transferred back to the lab on dry ice and stored at $-80{ }^{\circ} \mathrm{C}$ 
until analysis. Written informed consent was obtained from both donors prior to sample collection. All samples used were donated to Danone Nutricia Research in accordance with the Helsinki Declaration II.

\subsection{Whole Milk Proteolytic Digestion}

The in-solution digestion of whole milk was adapted from previous methods [61] and detailed in full [41]. Briefly, for bottom-up proteomics, whole milk proteins were denatured, reduced, and alkylated, followed by digestion with trypsin (Sigma-Aldrich, Steinheim, Germany) at $37^{\circ} \mathrm{C}$ for $16 \mathrm{~h}$. The resulting peptides were purified by solid phase extraction (SPE) using Oasis PRiME HLB 96-well plates (Waters, Etten-Leur, The Netherlands), according to the instructions of the manufacturer, dried by SpeedVac and stored at $-80^{\circ} \mathrm{C}$ until analysis. Prior to LC-MS/MS analysis the dried peptides were reconstituted in $2 \%$ formic acid (FA) to achieve an injection of $800 \mathrm{ng}$ material on column.

\subsection{Skimmed Milk Isolation of Endogenous Peptides}

Methods for skimmed milk peptide extraction have been previously described in detail [62]. Briefly, samples were defatted by centrifugation, $15 \mathrm{~min}$ at $1500 \times g$ at $4{ }^{\circ} \mathrm{C}$, followed by removal of proteins and impurities by precipitation with $20 \%$ trichloroacetic acid (TCA) (Sigma-Aldrich, Steinheim, Germany). TCA was added as equal volumes of milk and $20 \%(v / v)$ TCA, resulting in a final TCA concentration of $10 \%(v / v)$. The peptides extracted in the supernatant were purified by SPE using Oasis PRiME HLB 96 well plates (Waters, Etten-Leur, The Netherlands), dried by SpeedVac and stored at $-80^{\circ} \mathrm{C}$ until analysis. Prior to LC-MS/MS analysis the samples were reconstituted in $0.1 \%$ TFA and then further diluted in $2 \%$ FA to achieve an injection of $800 \mathrm{ng}$ of material on column.

\subsection{High-Pressure Liquid Chromatography Tandem Mass Spectrometry Glycopeptide Analysis}

Tryptic and endogenous peptides were injected on column as $800 \mathrm{ng}$, analyzed using an Agilent 1290 Infinity HPLC system (Agilent Technologies, Waldbronn, Germany) coupled on-line to an Orbitrap Fusion mass spectrometer (Thermo Fisher Scientific, San Jose, CA, USA) using a $120 \mathrm{~min}$ and $60 \mathrm{~min}$ gradient for tryptic and for endogenous peptides respectively. All samples were ran as MS triplicates with varying MS/MS fragmentation types as higher-energy collisional dissociation (HCD), HCD-product-dependent stepping collision energy HCD (HCD-pd-sHCD; see Supplemental Table S7 for triggering ions) and HCD-product-dependent electron-transfer/higher-energy collision dissociation (HCD-pd-EThcD).

The 60 min gradient was run as follows: $100 \%$ solvent $A$ for $5 \mathrm{~min}, 13-44 \%$ solvent $B$ for $40 \mathrm{~min}, 44-100 \%$ solvent B for $3 \mathrm{~min}, 100 \%$ solvent B for $2 \mathrm{~min}$, and $100 \%$ solvent A for $10 \mathrm{~min}$. The $120 \mathrm{~min}$ gradient was run with the same percentages of solvents A and B over double the gradient time. Peptides were ionized using a $2.0 \mathrm{kV}$ spray voltage. For the MS scan, the mass range was set to $\mathrm{m} / \mathrm{z} 350-2000$ for a maximum injection time of $50 \mathrm{~ms}$ at a mass resolution of 60,000 and an automatic gain control (AGC) target value of $4 \times 10^{5}$ in the Orbitrap mass analyzer. The dynamic exclusion time was set to $30 \mathrm{~s}$ for an exclusion window of $10 \mathrm{ppm}$ with a cycle time of $3 \mathrm{~s}$. Charge-state screening was enabled, and precursors with $2+$ to $8+$ charge states and intensities $>1 \times 10^{5}$ were selected for tandem mass spectrometry (MS/MS). HCD MS/MS ( $\mathrm{m} / \mathrm{z}$ 120-4000) acquisition was performed in the HCD cell, with the readout in the Orbitrap mass analyzer at a resolution of 30,000 (isolation window of $1.6 \mathrm{Th}$ ) and an AGC target value of $5 \times 10^{4}$ or a maximum injection time of $50 \mathrm{~ms}$ with a normalized collision energy (NCE) of 30\%. If at least three oxonium ions of glycopeptides (Supplemental Table S7) were observed, HCD-pd-sHCD or HCD$\mathrm{pd}-\mathrm{EThcD} \mathrm{MS} / \mathrm{MS}$ on the same precursor was triggered (mass tolerance of $20 \mathrm{ppm}$ ) and fragment ions $(\mathrm{m} / \mathrm{z} 120-4000)$ were analyzed in the Orbitrap mass analyzer at a resolution of 30,000 , AGC target value as $400 \%$ the standard value, or a maximum injection time of $250 \mathrm{~ms}$. Product-dependent sHCD was performed at NCEs of $10 \%, 25 \%$ and $40 \%$. Product-dependent EThcD was performed at supplemental collision energy of $25 \%$. 


\subsection{Glycopeptide Identification}

All the raw files obtained for the glycopeptide identification were processed in Byonic (Protein Metrics Inc, v. 3.9.4, Cupertino, CA, USA) searching against a human $\beta$-casein protein database (UniProtKB accession P05814, downloaded 22 September 2020) with the following search parameters: non-specific digestion with, precursor ion mass tolerance, 10 ppm; fragmentation type, both HCD \& EThcD; fragment mass tolerance, 20 ppm; no fixed modifications were included for the proteome or the peptidome (as the mature protein does not contain cysteins, carbamidomethylation is not necessary to consider); variable modifications: methionine oxidation, phosphorylation of serine and threonine as 7 common. For glycan analysis, we used a Byonic database of nine core 1 glycans (Supplemental Table S8). The list of nine glycans was defined following broader presearches using the built-in Byonic database of 70 human O-glycans. From the curated list of glycans, we acknowledge two limiting factors of our analysis approach; firstly, as we collected compositional information we principally do not distinguish between isomeric monosaccharides, e.g., GalNAc and GlcNAc residues; secondly, peptides which have been assigned with multiple $O$-glycans could instead carry one large glycan or a mixture of these mass-matching possibilities. The maximum number of precursors per scan was set to one and the FDR as $1 \%$. Data was further curated with non-negligible error probabilities $\mid \log$ Prob $\mid \geq 1.5$, Byonic score $\geq 150$, and Byonic Delta Modification score $>5$ deemed acceptable. Additionally, the signal peptide was removed, so only peptide sequences starting at amino acid position 16 (of the full protein sequence) were considered. Remaining reverse hits $(<1 \%)$ were removed for subsequent data analysis. Determination of curation criteria is detailed in Supplemental Table S2.

Data processing was done with Anaconda3 (2020.07) distribution of Python 3.8.3. Following data processing, all figures were generated with $\mathrm{R}$ version 3.4.2, using ggplot2 (version 2.2.1).

\subsection{Intact Protein Analysis by Mass Spectrometry \\ 4.6.1. Preparation of Human Milk Proteins for Intact Protein LC-MS and LC-MS/MS}

Samples were prepared for a final protein concentration of $4 \mu \mathrm{g} / \mu \mathrm{L}$. Skimmed milk samples, $40 \mu \mathrm{L}$, were prepared by adding $20 \mu \mathrm{L}$ Milli-Q water followed by the addition of $30 \mathrm{uL}$ of $100 \mathrm{mM}$ tris(2-carboxyethyl)phosphine hydrochloride (TCEP) and finally $10 \mu \mathrm{L}$ of $10 \%$ FA. Vortexing was performed in between each reagent addition. Samples were then incubated for $1 \mathrm{~h}$ at $60{ }^{\circ} \mathrm{C}$ under constant mixing. Following incubation, samples were filtered through a $0.45 \mu \mathrm{m}$ syringe filter (Waters, Etten-Leur, The Netherlands) and stored at $-20{ }^{\circ} \mathrm{C}$ until analysis. Prior to analysis the samples were diluted 8 times with $2 \%$ FA and a volume of $2 \mu \mathrm{L}$ containing $1 \mu \mathrm{g}$ of protein was used for the LC-MS/MS.

\subsubsection{Intact Protein LC-MS and LC-MS/MS Analyses}

Chromatographic separation of intact protein samples was conducted on a Thermo Scientific Vanquish Flex UHPLC (Thermo Fisher Scientific, Germering, Germany) system equipped with MAbPac RP $1 \times 150 \mathrm{~mm}$ column (Thermo Fisher Scientific, Germering, Germany). An amount of $1 \mu \mathrm{g}$ of protein was loaded on the column heated to $40{ }^{\circ} \mathrm{C}$. LC-MS/MS runtime was set to $27 \mathrm{~min}$ with flow rate of $100 \mu \mathrm{L} / \mathrm{min}$. Gradient elution was performed using mobile phases A (water/0.1\% FA) and B (ACN/0.1\% FA): $10 \% \mathrm{~B}$ for $5 \mathrm{~min}, 10-31 \%$ B for $1 \mathrm{~min}, 31-41 \%$ B for $14 \mathrm{~min}, 41-95 \%$ B for $1 \mathrm{~min}, 95 \%$ B for $1 \mathrm{~min}$, $95-10 \%$ B for $1 \mathrm{~min}$, and 4 min column equilibration back to $10 \%$ B. All intact protein MS experiments were performed on an Orbitrap Fusion Lumos Tribrid mass spectrometer (Thermo Fisher Scientific, San Jose, CA, USA) set to Intact Protein Mode with Low Pressure setting. For analysis of intact proteins, three methods were employed: low-resolution MS, high-resolution MS, and high-resolution MS/MS. The low- and high-resolution MS approaches were used for full MS acquisition and had resolutions (at $\mathrm{m} / \mathrm{z} 200)$ of 7500 and 120,000 , respectively. In the high-resolution MS/MS approach, the resolution parameter was defined at 120,000 for both full MS and data dependent MS/MS. Full MS scans in all 
methods were acquired for the range of $m / z$ 400-3000 with AGC target set to $2.5 \times 10^{6}$ $(250 \%)$. Maximum of injection time was defined at $250 \mathrm{~ms}$ with $5 \mu$ scans averaged for each scan. Data-dependent strategy was set to three scans per cycle. Selected ions were isolated with 4 Th window. Ion activation was set to ETD with a reaction time of $32 \mathrm{~ms}$, reagent target of $1 \mathrm{e} 6$ and maximum injection time of $200 \mathrm{~ms}$. All the data dependent MS/MS scans were recorded within the mass range of $m / z$ 300-4000 with AGC target set to $2 \times 10^{7}$ $(2000 \%)$ and maximum of injection time defined at $250 \mathrm{~ms}$. One $\mu$ scan was acquired.

\subsubsection{Database Generation for Intact Protein Analysis}

Database searching for intact protein LC-MS/MS analysis of human milk proteoforms was performed using the human $\beta$-casein (accession P05814) entry XML file downloaded from UniProtKB on 22 September 2020. The database imported from the XML file into ProSightPC 4.1 was treated as follows: initiator methionine removal, $\mathrm{N}$-terminal acetylation as well as other PTMs contained in the XML file were allowed; up to 13 features and maximum proteoform mass of $70 \mathrm{kDa}$ were allowed per sequence.

\subsubsection{Proteoform Library Generation for Matching of Intact Masses from LC-MS}

A library of proteoforms was generated to include human $\beta$-casein proteoforms with phosphorylation in the range of $0-5$ phosphorylated amino acid residues per sequence. For each phosphoproteoform, glycoproteoforms with 0-2 O-glycans were generated. The O-glycans considered are described in Supplemental Table S8. Proteoform monoisotopic and average masses were calculated based on the amino acid sequence of the mature protein (UniProtKB accession P05814, downloaded 22 September 2020, fragment 16-226) and the additional masses of the respective PTMs.

\subsubsection{Data Analysis for Intact Mass LC-MS and LC-MS/MS}

Isotopically resolved and unresolved spectra obtained in intact protein LC-MS experiments of human milk proteins were deconvoluted with the BioPharma Finder 3.2 Software using Xtract or ReSpect algorithms (Thermo Fisher Scientific, San Jose, CA, USA), respectively. The Xtract parameters were as follows: signal-to-noise (S/N) threshold $3 ; \mathrm{m} / \mathrm{z}$ range 400-3000, charge range 2-50, and minimum number of detected charge states of 3 . The source spectra were generated using the sliding windows algorithm with the following parameters: merge tolerance of $30 \mathrm{ppm}$, maximum retention time gap of $1 \mathrm{~min}$ and a minimum number of detected intervals of 3 . ReSpect parameters: precursor $\mathrm{m} / \mathrm{z}$ range 400-3000 and deconvolution mass tolerance $20 \mathrm{ppm}$. The source spectra were generated using the same sliding windows algorithm detailed for Xtract.

Automatic searches were performed using the Thermo Proteome Discoverer software (version 2.4.0.305, San Jose, CA, USA) with use of ProSightPD nodes for the high-resolution MS/MS experimental workflow. Two ProSightPD Annotated Proteoform nodes and the ProSightPD Subsequence Search node were run in parallel at 20, 500, and $20 \mathrm{ppm}$ precursor mass tolerances, respectively. Fragment mass tolerance was in all three cases set to $20 \mathrm{ppm}$.

The deconvoluted monoisotopic masses from the high-resolution LC-MS files were matched within a window of $+/-1$ Da to the precursor masses from the proteoform spectrum match (PrSM) table of the ProSightPD search results. Accession number was annotated for the proteoforms with matching masses and retention times within a window of + / $-1 \mathrm{~min}$. The deconvoluted masses from both high- and low-resolution LC-MS were also matched within a window of $+/-1$ Da against the library of theoretical masses of human $\beta$-casein proteoforms. Where possible, proteoforms were annotated based on both LC-MS/MS database search identification and on theoretical mass match. In cases where no identification was made by database search, proteoforms were annotated by matching of their experimental masses to theoretical masses with the condition that they eluted in a window of $+/-1 \mathrm{~min}$ from proteoforms identified by database search. Proteoform intensity was normalized on the sum of proteoform intensities for each protein. 


\section{Conclusions}

Having a complete understanding of the human milk phospho- and glyco- proteome and endogenous peptidome is critical for a better understanding of the structure / function relationship of modified proteins and peptides. We have shown here that the endogenous peptidome is an unexplored source of PTM-rich peptides, wherein we have highlighted diverse and abundant phosphorylation and O-glycosylation of $\beta$-casein. Our work here lays a foundation for uncovering new PTMs in the human milk proteome and the endogenous peptidome that can be used in future studies to investigate functionality.

Supplementary Materials: Supplementary materials can be found at https://www.mdpi.com/ article/10.3390/ijms22158140/s1.

Author Contributions: K.A.D., K.R.R. and A.J.R.H. conceptualized the project; K.A.D. performed all experiments; K.A.D., I.G. and K.R.R. were responsible for the data curation and analysis; K.A.D., I.G. and H.W.P.v.d.T. were responsible for visualization; B.S. and A.J.R.H. provided resources; K.A.D. and K.R.R. were responsible for the writing; I.G., M.M., B.S. and A.J.R.H. were responsible for editing. All authors have read and agreed to the published version of the manuscript.

Funding: We acknowledge support from the Netherlands Organization for Scientific Research (NWO) funding the Netherlands Proteomics Centre through the X-omics Road Map program (project 184.034.019). A.J.R.H and I.G acknowledges additional support from NWO in the framework of the Innovation Fund for Chemistry (project 731.017.202). K.R.R. acknowledges support from NWO Veni project VI.Veni.192.058. Additional support for this research was provided by Danone Nutricia Research.

Institutional Review Board Statement: Written informed consent was obtained prior to sample collection. All samples used were anonymized and donated to Danone Nutricia Research in accordance with the Helsinki Declaration II. Sample donation and relevant demographic and health information was voluntary.

Informed Consent Statement: Informed consent was obtained from all subjects involved in the study.

Data Availability Statement: The mass spectrometry proteomics data have been deposited to the MassIVE repository and can be accessed from the following link: ftp:/ / massive.ucsd.edu/MSV0 00087464/. Additionally, all plotted LFQ non-glyco proteome and peptidome data has been made available for user interaction at the following link: (https://milkprofiling.hecklab.com/). All Rscripts have been published on https:/ / github.com/hecklab/glyco-peptidome.

Acknowledgments: We would like to acknowledge the donors for their support in providing the milk samples, and Harm Post (Hecklab, Utrecht University) for help with sample collection and transportation. Additionally, we thank Jing Zhu (formerly Hecklab, Utrecht University) for digested protein samples and Sem Tamara (Hecklab, Utrecht University) for help with creating MS methods for the intact protein experiments and guidance on analyzing the data.

Conflicts of Interest: M.M. and B.S. are employees of Danone Nutricia Research. K.A.D was enrolled as PhD student at Utrecht University during this study and received financial support from Danone Nutricia Research. None of the authors have further conflicts of interest with regard to the content of this manuscript.

\section{References}

1. Wu, X.; Jackson, R.T.; Khan, S.A.; Ahuja, J.; Pehrsson, P.R. Human milk nutrient composition in the United States: Current knowledge, challenges, and research needs. Curr. Dev. Nutr. 2018, 2, nzy025. [CrossRef]

2. Donovan, S.M. Human milk proteins: Composition and physiological significance. Nestle Nutr. Inst. Workshop Ser. 2019, 90, 93-101. [CrossRef]

3. Andreas, N.J.; Kampmann, B.; Mehring Le-Doare, K. Human breast milk: A review on its composition and bioactivity. Early Hum. Dev. 2015, 91, 629-635. [CrossRef] [PubMed]

4. Liao, Y.; Weber, D.; Xu, W.; Durbin-Johnson, B.P.; Phinney, B.S.; Lonnerdal, B. Absolute quantification of human milk caseins and the whey/casein ratio during the first year of lactation. J. Proteome Res. 2017, 16, 4113-4121. [CrossRef]

5. Loos, R.J.F. From nutrigenomics to personalizing diets: Are we ready for precision medicine? Am. J. Clin. Nutr. 2019, 109, 1-2. [CrossRef] 
6. Bode, L.; Raman, A.S.; Murch, S.H.; Rollins, N.C.; Gordon, J.I. Understanding the mother-breastmilk-infant "triad". Science 2020, 367, 1070-1072. [CrossRef]

7. Nielsen, S.D.; Beverly, R.L.; Qu, Y.; Dallas, D.C. Milk bioactive peptide database: A comprehensive database of milk proteinderived bioactive peptides and novel visualization. Food Chem. 2017, 232, 673-682. [CrossRef]

8. Atkinson, S.A.; Lönnerdal, B.O. B-nonprotein nitrogen fractions of human milk. In Handbook of Milk Composition; Jensen, R.G., Ed.; Academic Press: San Diego, CA, USA, 1995; pp. 369-387. [CrossRef]

9. Ross, S.A.; Clark, R.M. Nitrogen distribution in human milk from 2 to 16 weeks postpartum. J. Dairy Sci. 1985, 68, 3199-3201. [CrossRef]

10. Carlson, S.E. Human milk nonprotein nitrogen: Occurrence and possible functions. Adv. Pediatr. 1985, 32, 43-70.

11. Dallas, D.C.; Smink, C.J.; Robinson, R.C.; Tian, T.; Guerrero, A.; Parker, E.A.; Smilowitz, J.T.; Hettinga, K.A.; Underwood, M.A.; Lebrilla, C.B.; et al. Endogenous human milk peptide release is greater after preterm birth than term birth. J. Nutr. 2015, 145, 425-433. [CrossRef]

12. Guerrero, A.; Dallas, D.C.; Contreras, S.; Chee, S.; Parker, E.A.; Sun, X.; Dimapasoc, L.; Barile, D.; German, J.B.; Lebrilla, C.B Mechanistic peptidomics: Factors that dictate specificity in the formation of endogenous peptides in human milk. Mol. Cell. Proteom. 2014, 13, 3343-3351. [CrossRef]

13. Wan, J.; Cui, X.W.; Zhang, J.; Fu, Z.Y.; Guo, X.R.; Sun, L.Z.; Ji, C.B. Peptidome analysis of human skim milk in term and preterm milk. Biochem. Biophys. Res. Commun. 2013, 438, 236-241. [CrossRef] [PubMed]

14. Dingess, K.A.; de Waard, M.; Boeren, S.; Vervoort, J.; Lambers, T.T.; van Goudoever, J.B.; Hettinga, K. Human milk peptides differentiate between the preterm and term infant and across varying lactational stages. Food Funct. 2017, 8, 3769-3782. [CrossRef]

15. Dallas, D.C.; Guerrero, A.; Khaldi, N.; Castillo, P.A.; Martin, W.F.; Smilowitz, J.T.; Bevins, C.L.; Barile, D.; German, J.B.; Lebrilla, C.B. Extensive In Vivo human milk peptidomics reveals specific proteolysis yielding protective antimicrobial peptides. J. Proteome Res. 2013, 12, 2295-2304. [CrossRef]

16. Elzoghby, A.O.; Abo El-Fotoh, W.S.; Elgindy, N.A. Casein-based formulations as promising controlled release drug delivery systems. J. Control. Release 2011, 153, 206-216. [CrossRef] [PubMed]

17. Głąb, T.K.; Boratyński, J. Potential of casein as a carrier for biologically active agents. Top. Curr. Chem. 2017, 375, 71. [CrossRef]

18. Dallas, D.C.; German, J.B. Enzymes in human milk. Nestle Nutr. Inst. Workshop Ser. 2017, 88, 129-136. [CrossRef]

19. Lönnerdal, B. Human milk proteins. In Protecting Infants through Human Milk; Springer: Boston, MA, USA, $2004 ;$ pp. 11-25.

20. Lonnerdal, B. Bioactive proteins in human milk: Health, nutrition, and implications for infant formulas. J. Pediatr. 2016, 173, S4-S9. [CrossRef]

21. Beverly, R.L.; Huston, R.K.; Markell, A.M.; McCulley, E.A.; Martin, R.L.; Dallas, D.C. Differences in human milk peptide release along the gastrointestinal tract between preterm and term infants. Clin. Nutr. 2020. [CrossRef]

22. Beverly, R.L.; Huston, R.K.; Markell, A.M.; McCulley, E.A.; Martin, R.L.; Dallas, D.C. Milk peptides survive In Vivo gastrointestinal digestion and are excreted in the stool of infants. J. Nutr. 2019, 150, 712-721. [CrossRef]

23. Nielsen, S.D.; Beverly, R.L.; Dallas, D.C. Peptides released from foremilk and hindmilk proteins by breast milk proteases are highly similar. Front. Nutr. 2017, 4, 54. [CrossRef] [PubMed]

24. Dallas, D.C.; Guerrero, A.; Khaldi, N.; Borghese, R.; Bhandari, A.; Underwood, M.A.; Lebrilla, C.B.; German, J.B.; Barile, D. A peptidomic analysis of human milk digestion in the infant stomach reveals protein-specific degradation patterns. J. Nutr. 2014, 144, 815-820. [CrossRef]

25. Deglaire, A.; Oliveira, S.; Jardin, J.; Briard-Bion, V.; Kroell, F.; Emily, M.; Ménard, O.; Bourlieu, C.; Dupont, D. Impact of human milk pasteurization on the kinetics of peptide release during In Vitro dynamic digestion at the preterm newborn stage. Food Chem. 2019, 281, 294-303. [CrossRef]

26. Khaldi, N.; Vijayakumar, V.; Dallas, D.C.; Guerrero, A.; Wickramasinghe, S.; Smilowitz, J.T.; Medrano, J.F.; Lebrilla, C.B.; Shields, D.C.; German, J.B. Predicting the important enzymes in human breast milk digestion. J. Agric. Food Chem. 2014, 62, 7225-7232. [CrossRef]

27. Minervini, F.; Algaron, F.; Rizzello, C.G.; Fox, P.F.; Monnet, V.; Gobbetti, M. Angiotensin I-converting-enzyme-inhibitory and antibacterial peptides from Lactobacillus helveticus PR4 proteinase-hydrolyzed caseins of milk from six species. Appl. Environ. Microbiol. 2003, 69, 5297-5305. [CrossRef]

28. Sun, Y.; Zhou, Y.; Liu, X.; Zhang, F.; Yan, L.; Chen, L.; Wang, X.; Ruan, H.; Ji, C.; Cui, X.; et al. Antimicrobial activity and mechanism of PDC213, an endogenous peptide from human milk. Biochem. Biophys. Res. Commun. 2017, 484, 132-137. [CrossRef] [PubMed]

29. Zhang, F.; Cui, X.; Fu, Y.; Zhang, J.; Zhou, Y.; Sun, Y.; Wang, X.; Li, Y.; Liu, Q.; Chen, T. Antimicrobial activity and mechanism of the human milk-sourced peptide Casein201. Biochem. Biophys. Res. Commun. 2017, 485, 698-704. [CrossRef]

30. Wang, X.; Sun, Y.; Wang, F.; You, L.; Cao, Y.; Tang, R.; Wen, J.; Cui, X. A novel endogenous antimicrobial peptide CAMP(211-225) derived from casein in human milk. Food Funct. 2020, 11, 2291-2298. [CrossRef]

31. Molinari, C.E.; Casadio, Y.S.; Hartmann, B.T.; Arthur, P.G.; Hartmann, P.E. Longitudinal analysis of protein glycosylation and beta-casein phosphorylation in term and preterm human milk during the first 2 months of lactation. Br. J. Nutr. 2013, 110, 105-115. [CrossRef] [PubMed] 
32. Bouhallab, S.; Bouglé, D. Biopeptides of milk: Caseinophosphopeptides and mineral bioavailability. Reprod. Nutr. Dev. 2004, 44, 493-498. [CrossRef]

33. Kornfeld, R.; Kornfeld, S. Assembly of asparagine-linked oligosaccharides. Annu. Rev. Biochem. 1985, 54, 631-664. [CrossRef]

34. Hart, G.W.; Haltiwanger, R.S.; Holt, G.D.; Kelly, W.G. Glycosylation in the nucleus and cytoplasm. Annu. Rev. Biochem. 1989, 58, 841-874. [CrossRef]

35. Froehlich, J.W.; Dodds, E.D.; Barboza, M.; McJimpsey, E.L.; Seipert, R.R.; Francis, J.; An, H.J.; Freeman, S.; German, J.B.; Lebrilla, C.B. Glycoprotein expression in human milk during lactation. J. Agric. Food Chem. 2010, 58, 6440-6448. [CrossRef]

36. Varki, A. Biological roles of oligosaccharides: All of the theories are correct. Glycobiology 1993, 3, 97-130. [CrossRef] [PubMed]

37. Smilowitz, J.T.; Lebrilla, C.B.; Mills, D.A.; German, J.B.; Freeman, S.L. Breast milk oligosaccharides: Structure-function relationships in the neonate. Annu. Rev. Nutr. 2014, 34, 143-169. [CrossRef] [PubMed]

38. Eidelman, A.I.; Schanler, R.J. Breastfeeding and the use of human milk. Pediatrics 2012, 129, e827-e841. [CrossRef]

39. Ballard, O.; Morrow, A.L. Human milk composition: Nutrients and bioactive factors. Pediatr. Clin. N. Am. 2013, 60, 49-74. [CrossRef]

40. Lemay, D.G.; Ballard, O.A.; Hughes, M.A.; Morrow, A.L.; Horseman, N.D.; Nommsen-Rivers, L.A. RNA sequencing of the human milk fat layer transcriptome reveals distinct gene expression profiles at three stages of lactation. PLoS ONE 2013, 8, e67531. [CrossRef]

41. Zhu, J.; Dingess, K.A.; Mank, M.; Stahl, B.; Heck, A.J.R. Personalized profiling reveals donor- and lactation-specific trends in the human milk proteome and peptidome. J. Nutr. 2021. [CrossRef] [PubMed]

42. Reiding, K.R.; Bondt, A.; Franc, V.; Heck, A.J.R. The benefits of hybrid fragmentation methods for glycoproteomics. TrAC Trends Anal. Chem. 2018, 108, 260-268. [CrossRef]

43. Riley, N.M.; Hebert, A.S.; Westphall, M.S.; Coon, J.J. Capturing site-specific heterogeneity with large-scale N-glycoproteome analysis. Nat. Commun. 2019, 10, 1311. [CrossRef]

44. Liu, M.Q.; Zeng, W.F.; Fang, P.; Cao, W.Q.; Liu, C.; Yan, G.Q.; Zhang, Y.; Peng, C.; Wu, J.Q.; Zhang, X.J.; et al. pGlyco 2.0 enables precision $\mathrm{N}$-glycoproteomics with comprehensive quality control and one-step mass spectrometry for intact glycopeptide identification. Nat. Commun. 2017, 8, 438. [CrossRef]

45. Ferranti, P.; Traisci, M.V.; Picariello, G.; Nasi, A.; Boschi, V.; Siervo, M.; Falconi, C.; Chianese, L.; Addeo, F. Casein proteolysis in human milk: Tracing the pattern of casein breakdown and the formation of potential bioactive peptides. J. Dairy Res. 2004, 71, 74-87. [CrossRef]

46. Manso, M.A.; Miguel, M.; López-Fandiño, R. Application of capillary zone electrophoresis to the characterisation of the human milk protein profile and its evolution throughout lactation. J. Chromatogr. A 2007, 1146, 110-117. [CrossRef] [PubMed]

47. Neville, M.C.; Keller, R.P.; Casey, C.; Allen, J.C. Calcium partitioning in human and bovine milk. J. Dairy Sci. 1994, 77, 1964-1975. [CrossRef]

48. Froehlich, J.W.; Chu, C.S.; Tang, N.; Waddell, K.; Grimm, R.; Lebrilla, C.B. Label-free liquid chromatography-tandem mass spectrometry analysis with automated phosphopeptide enrichment reveals dynamic human milk protein phosphorylation during lactation. Anal. Biochem. 2011, 408, 136-146. [CrossRef]

49. Poth, A.G.; Deeth, H.C.; Alewood, P.F.; Holland, J.W. Analysis of the human casein phosphoproteome by 2-D electrophoresis and MALDI-TOF/TOF MS reveals new phosphoforms. J. Proteome Res. 2008, 7, 5017-5027. [CrossRef]

50. Greenberg, R.; Groves, M.L.; Dower, H.J. Human beta-casein. Amino acid sequence and identification of phosphorylation sites. J. Biol. Chem. 1984, 259, 5132-5138. [CrossRef]

51. Kroening, T.A.; Baxter, J.H.; Anderson, S.A.; Hards, R.G.; Harvey, L.; Mukerji, P. Concentrations and anti-Haemophilus influenzae activities of beta-casein phosphoforms in human milk. J. Pediatr. Gastroenterol. Nutr. 1999, 28, 486-491. [CrossRef] [PubMed]

52. Tagliabracci, V.S.; Engel, J.L.; Wen, J.; Wiley, S.E.; Worby, C.A.; Kinch, L.N.; Xiao, J.; Grishin, N.V.; Dixon, J.E. Secreted kinase phosphorylates extracellular proteins that regulate biomineralization. Science 2012, 336, 1150-1153. [CrossRef]

53. Tagliabracci, V.S.; Wiley, S.E.; Guo, X.; Kinch, L.N.; Durrant, E.; Wen, J.; Xiao, J.; Cui, J.; Nguyen, K.B.; Engel, J.L.; et al. A single kinase generates the majority of the secreted phosphoproteome. Cell 2015, 161, 1619-1632. [CrossRef] [PubMed]

54. Riley, N.M.; Malaker, S.A.; Driessen, M.D.; Bertozzi, C.R. Optimal dissociation methods differ for N- and O-glycopeptides. J. Proteome Res. 2020, 19, 3286-3301. [CrossRef] [PubMed]

55. MacLean, B.; Tomazela, D.M.; Shulman, N.; Chambers, M.; Finney, G.L.; Frewen, B.; Kern, R.; Tabb, D.L.; Liebler, D.C.; MacCoss, M.J. Skyline: An open source document editor for creating and analyzing targeted proteomics experiments. Bioinformatics 2010, 26, 966-968. [CrossRef]

56. Reiding, K.R.; Franc, V.; Huitema, M.G.; Brouwer, E.; Heeringa, P.; Heck, A.J.R. Neutrophil myeloperoxidase harbors distinct site-specific peculiarities in its glycosylation. J. Biol. Chem. 2019, 294, 20233-20245. [CrossRef] [PubMed]

57. Goonatilleke, E.; Huang, J.; Xu, G.; Wu, L.; Smilowitz, J.T.; German, J.B.; Lebrilla, C.B. Human milk proteins and their glycosylation exhibit quantitative dynamic variations during lactation. J. Nutr. 2019. [CrossRef]

58. Zhu, J.; Lin, Y.H.; Dingess, K.A.; Mank, M.; Stahl, B.; Heck, A.J.R. Quantitative longitudinal inventory of the N-glycoproteome of human milk from a single donor reveals the highly variable repertoire and dynamic site-specific changes. J. Proteome Res. 2020, 19, 1941-1952. [CrossRef] [PubMed] 
59. Dev, B.C.; Sood, S.M.; DeWind, S.; Slattery, C.W. Kappa-casein and beta-caseins in human milk micelles: Structural studies. Arch. Biochem. Biophys. 1994, 314, 329-336. [CrossRef] [PubMed]

60. Geraghty, S.R.; Davidson, B.S.; Warner, B.B.; Sapsford, A.L.; Ballard, J.L.; List, B.A.; Akers, R.; Morrow, A.L. The development of a research human milk bank. J. Hum. Lact. 2005, 21, 59-66. [CrossRef]

61. Zhu, J.; Garrigues, L.; Van den Toorn, H.; Stahl, B.; Heck, A.J.R. Discovery and quantification of non-human proteins in human milk. J. Proteome Res. 2018. [CrossRef]

62. Dingess, K.A.; van den Toorn, H.W.P.; Mank, M.; Stahl, B.; Heck, A.J.R. Toward an efficient workflow for the analysis of the human milk peptidome. Anal. Bioanal. Chem. 2019, 411, 1351-1363. [CrossRef] [PubMed] 